Seton Hall University eRepository@Seton Hall

Seton Hall University Dissertations and Theses (ETDs)

Seton Hall University Dissertations and Theses

Spring 3-2-2015

\title{
Educational Opportunity Fund Program and Community College Student Retention
}

Aretha Watson

aretha.watson@student.shu.edu

Follow this and additional works at: https://scholarship.shu.edu/dissertations

Part of the Educational Administration and Supervision Commons, and the Higher Education Commons

\section{Recommended Citation}

Watson, Aretha, "Educational Opportunity Fund Program and Community College Student Retention" (2015). Seton Hall University Dissertations and Theses (ETDs). 2065.

https://scholarship.shu.edu/dissertations/2065 


\title{
Educational Opportunity Fund Program and Community College

\author{
Student Retention
}

\section{by}

\author{
Aretha Watson
}

Submitted in partial fulfillment of the requirements for the degree Doctor of Philosophy (Education)

Department of

Seton Hall University

2015 
(C) 2015 Aretha Watson 


\author{
SETON HALL UNIVERSITY \\ COLLEGE OF EDUCATION AND HUMAN SERVICES \\ OFFICE OF GRADUATE STUDIES
}

\title{
APPROVAL FOR SUCCESSFUL DEFENSE
}

Doctoral Candidate, Aretha Watson, has successfully defended and made the required modifications to the text of the doctoral dissertation for the Ph.D. during this Spring Semester 2015.

\section{DISSERTATION COMMITTEE \\ (please sign and date beside your name)}

Mentor:

Dr. Rong Chen

$3 / 2 / 20 / 5$

Committee Member:

Dr. Fannie Gordon

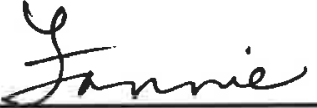

\&

andor

$3-2-15$

Committee Member:

Dr. Eunyoung Kim

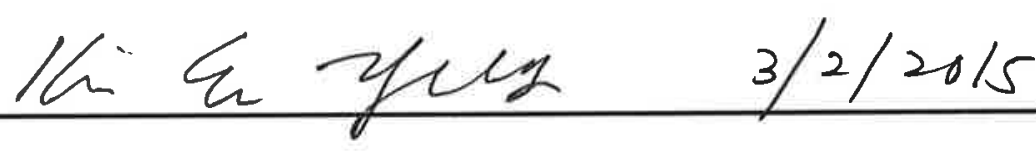

The mentor and any other committee members who wish to review revisions will sign and date this document only when revisions have been completed. Please return this form to the Office of Graduate Studies, where it will be placed in the candidate's file and submit a copy with your final dissertation to be bound as page number two. 


\begin{abstract}
The EOF program is a state funded student support services program designed to provide access and financial support to disadvantaged students, and to improve student success as measured by student retention and graduation rates. This research examined the effects of EOF program and other factors on first semester retention in a community college. . Three models were developed: baseline model (whole group), and two subgroup models (EOF and comparable non-EOF). Logistic regression analysis revealed that participation in EOF was positively related to student retention at the end of the first semester. Gender, race/ethnicity, college placement test (reading and math), and first semester GPA were also statistically significant in the baseline model and comparable non-EOF model. Additionally, results indicate that, compared to the comparable nonEOF group, EOF students tended to have reduced gaps in retention by gender or race/ethnicity. The results of this study provide empirical support that institutional administrators and state policy makers should increase the amount of funding allocated for EOF, to ultimately increase the number of students who can participate in the program. Future research should focus on replicating this study at multiple community colleges and four-year institutions, and a program evaluation for the EOF program could offer additional insight into first semester student retention.

Keywords: EOF, educational opportunity fund, state-funded, support services programs, retention, community college, low-income, first semester, comparable group, and developmental courses
\end{abstract}




\section{DEDICATION}

To my husband, Gary Watson and daughter Alexandra Watson for their love, inspiration, and encouragement. 


\section{ACKNOWLEDGMENTS}

My sincere heartfelt appreciation is extended to the members of my dissertation committee who provided guidance and direction. I acknowledge Dr. Rong Chen, my dissertation chair, for her support for the past 7 years. I was extremely nervous about entering the doctoral program, but those fears were eased after meeting with Dr. Chen for the first time. I was fortunate to take several courses with her over the years, all of which forced me to critically analyze who I was as an educator and an individual. Through her desire for scholarly research, I have been encouraged to aim for opportunities to contribute to the research agenda that addresses my area(s) of interest. I am also grateful to the other members of my committee: Dr. Eunyoung Kim and Dr. Fannie Gordon. Their scrutiny and scholarly contributions helped to add substance to this document, and their advising and mentorship has helped to make me a better scholar and researcher.

A special thanks to my parents Jacqueline \& Dewitt Bacon, who have always had faith in my academic goals. I am especially thankful to my mother who left her home country of Guyana to move to America for my brother and I to have a better life. This $\mathrm{Ph} . \mathrm{D}$. is not only for me, but also for my mother who has worked so hard all her life to give me everything I needed. She has shown me what hard work is, and how to never give up on my dreams.

I am grateful to all my family and friends who have shown me so much support in the last seven years to achieve my goal of being the first person in my family to earn a doctorate. Their constant words of encouragement have helped me to stay committed to finishing this degree. 
I have to thank my daughter, Alexandra, who has been amazing through this journey. She was four when I started, and is now a beautiful young lady. I thank her for all the words of encouragement each time I was in my office and she saw me frustrated. She would come in and say, "I know you can do it mommy." Those words helped me to move forward, and to complete each chapter.

Finally, I would like to thank my amazing husband, Gary, who never doubted my ability to complete this dissertation. You have been there for me since the beginning of my educational journey. You were my greatest cheerleader as I pursued my bachelor's, master's, and this doctoral degree! Perhaps, more than any other individual, Gary has listened faithfully to hours of discussion about my dissertation topic. In spite of my frustrations, he always knew how to keep me motivated and showered me with compliments about my writing when I doubted myself the most. To him, I am forever grateful. 


\section{TABLE OF CONTENTS}

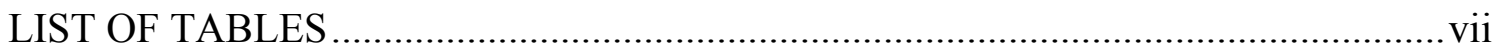

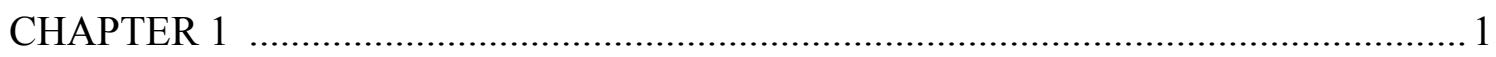

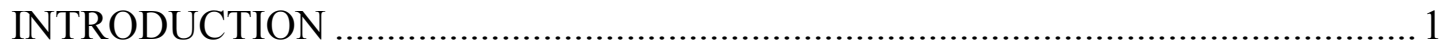

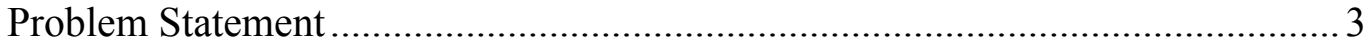

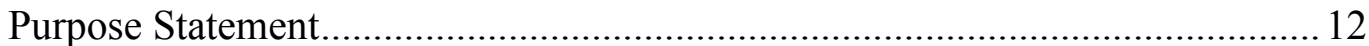

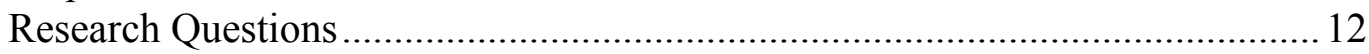

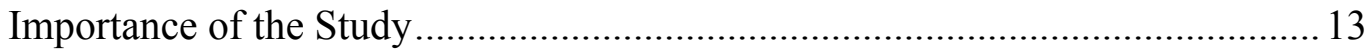

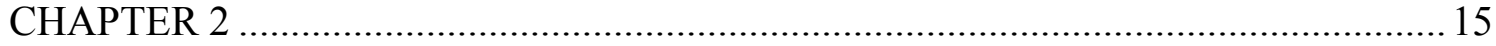

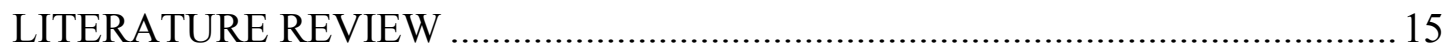

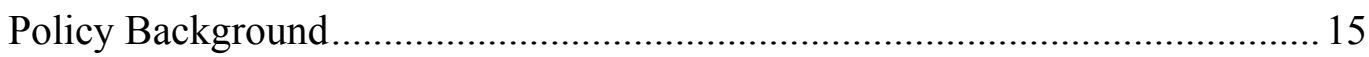

Defining Student Retention.............................................................................. 19

Theoretical Models of College Student Retention...............................................23

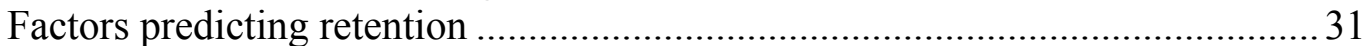

Age

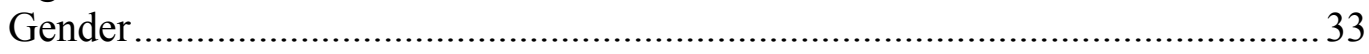

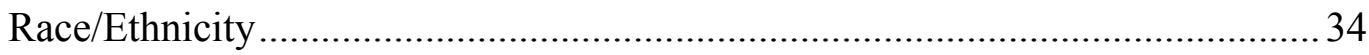

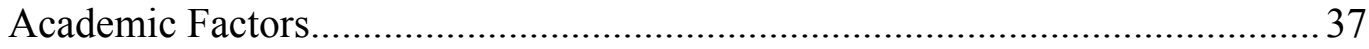

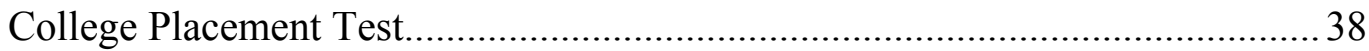

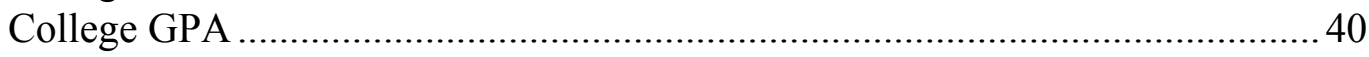

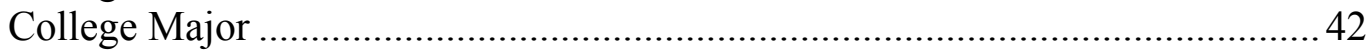

State-funded Programs .................................................................................. 43

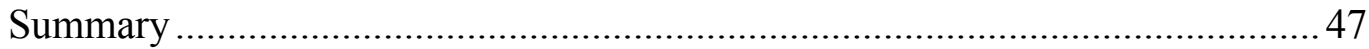

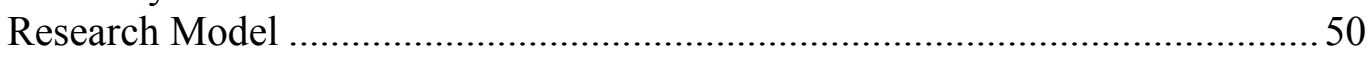

CHAPTER 3 …

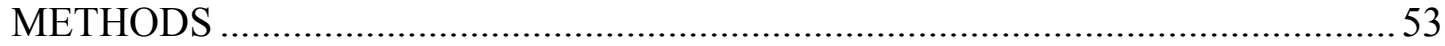

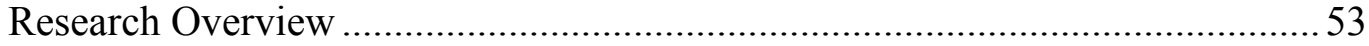

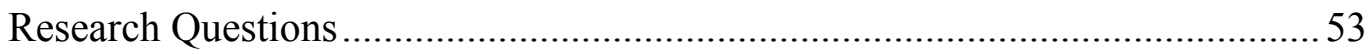

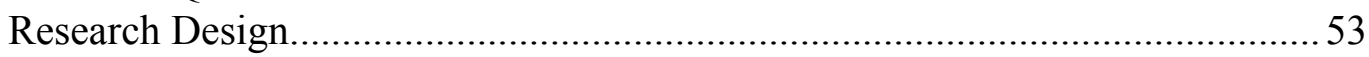

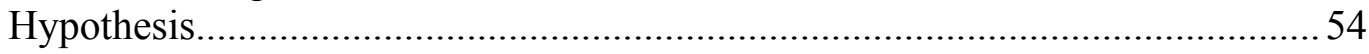

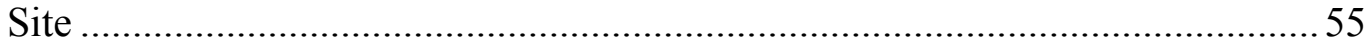

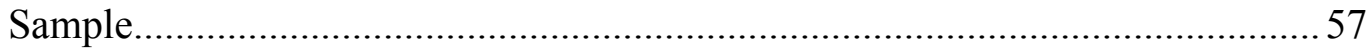

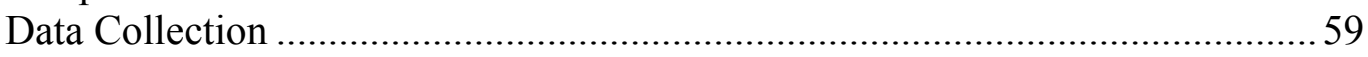

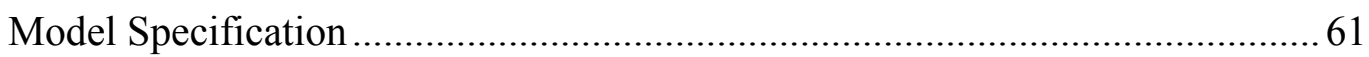

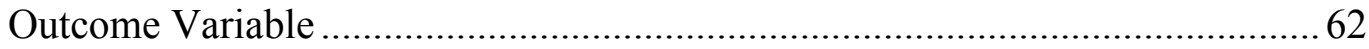

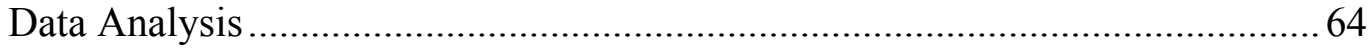

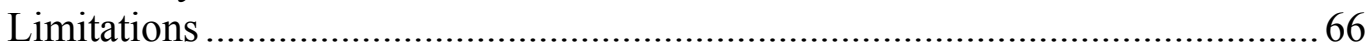

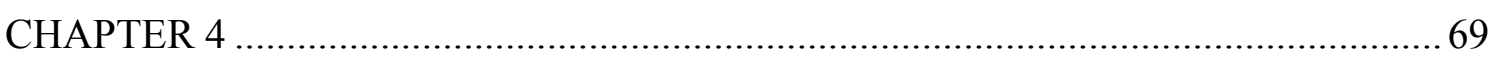

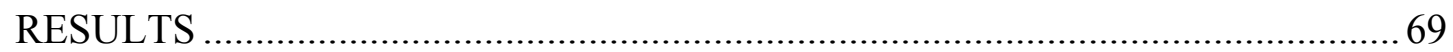

Descriptive Analysis ...................................................................................

Categorical Variables ..................................................................................... 70 


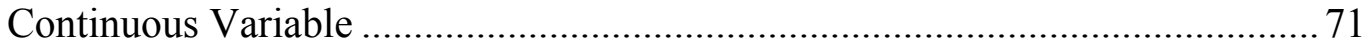

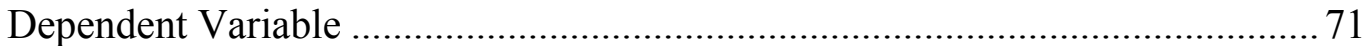

Cross Tabulations for Student Characteristic and Retention ...............................72

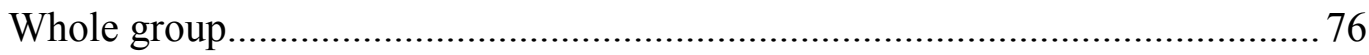

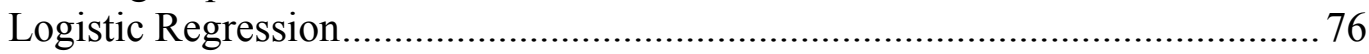

Baseline Model ................................................................................. 76

Subgroup Analysis .................................................................................. 80

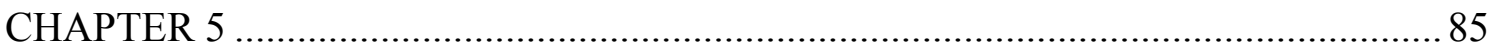

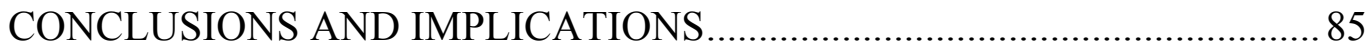

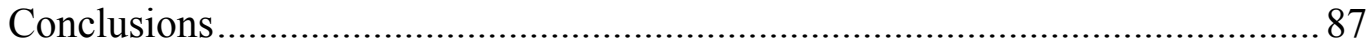

Implications for Policy and Practices ................................................................... 89

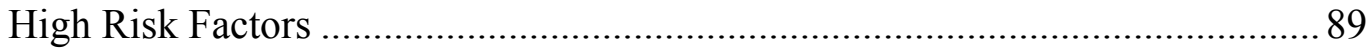

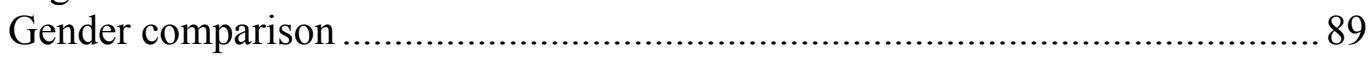

Race/Ethnicity comparison ........................................................................... 90

College placement..................................................................................... 91

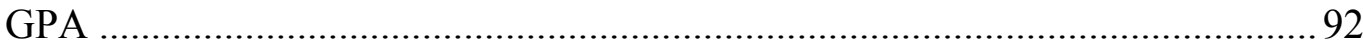

EOF Program and Retention ......................................................................... 93

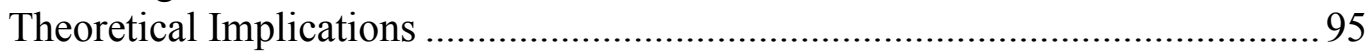

Implications for Future Research ......................................................................95

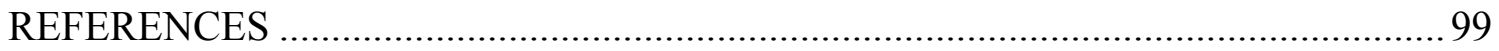




\section{LIST OF TABLES}

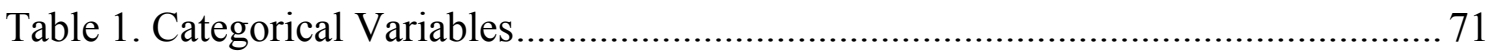

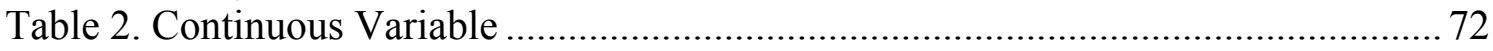

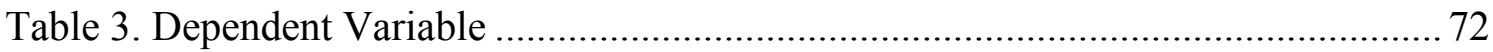

Table 4. Crosstabs for Student Characteristics: Whole Sample .................................. 74

Table 5. Crosstabs for Student Characteristics: EOF Sample ...................................... 75

Table 6. Crosstabs for Student Characteristics: Non-EOF Sample ................................ 76

Table 7. Logistic Regression Results for the Whole Sample......................................... 77

Table 8. Logistic Regression Results for the EOF Sample....................................... 81

Table 9. Logistic Regression Results for the Non-EOF Sample .................................. 82 


\section{CHAPTER 1 \\ INTRODUCTION}

Starting in the 20th century with the first junior college, Joliet Community College in Illinois (Crisp \& Mina, 2012), community colleges became arguably one of the most significant developments in American higher education. The growth in number of community colleges was driven by the development of the Industrial Revolution, a longer period of adolescence, and the drive for social equality (Cofer \& Somers, 2001; Cohen \& Brawer, 2003; Crisp \& Mina, 2012). Specifically, they took on the load of teaching general education courses so that universities would not have the burden of teaching general education (Brooks-Leonard, 1991). During the course of its history, the community college continued to serve multiple missions. Moreover, it served diverse populations and further educated a large segment of the population by attempting to accomplish a number of contradictory missions (Crisp \& Mina, 2012) such as: (a) promote social equality and increase economic efficiency, (b) provide students with a common cultural heritage and sort them into a specialized curriculum, (c) meet the demands of employers and state planners for differentiated education, and (d) provide general education for citizens within a democratic society while providing technical training for workers in an advanced industrial economy (Brint \& Karabel, 1989; Cohen \& Brawer, 2003; Crisp \& Mina, 2012).

After World War II, America saw expansion in the community college sector as a new means of promoting access to higher education; this came in conjunction with a need to educate the U.S. population beyond high school (Crisp \& Mina, 2012). Moving forward, 
community colleges grew at a rapid rate during the 1950s, 1960s, and 1970s. This increase occurred due to the Government Issue (GI) Bill, the Civil Rights Movement, the Women's Movement, and the Baby Boom, all of which influenced the reach of community colleges (Crisp \& Mina, 2012). For example: In 1965, about $74 \%$ of all students in public, degreegranting institutions attended four-year schools, whereas in the same year only $26 \%$ attended two-year community colleges (Kasper, 2002). In the following decade, $60 \%$ of community college students were men. By 1999, minority enrollment had increased to $33 \%$; before that minority enrollment had only been approximately $20 \%$ (Kasper, 2002). As of 2012, an estimated 7.2 million students had enrolled in more than 1,700 community colleges, which accounted for $40 \%$ of the total undergraduate enrollment in the United States (National Center for Educational Statistics, 2012). At the conclusion of this study, community college enrollment was almost half of the total amount for higher education, which reflected the prominent role that community colleges play in American higher education.

Despite this, the characteristics of community college students were, in many respects, distinctive from those of traditional students attending four-year institutions. Specifically, community college students:

- were non-traditional

- had dependents

- were single parents

- struggled with financial independence

- delayed enrollment after high school

- attended college part time 
- lacked high school diplomas

- were academically underprepared

- were often enrolled in developmental education courses

- commuted to campus

- worked full-time (Burns, 2010; Center for Community College Student Engagement, 2011; Complete College America, 2011; Fike \& Fike, 2008; Hoachlander, Sikora, Horn, \& Carroll, 2003; U.S. Department of Education, 2011).

\section{Problem Statement}

In addition, the role of community college evolved with increased enrollment. Recently, community colleges were charged with a new set of challenges: (a) close the achievement gaps for students, (b) increase course and program completion rates, (c) provide evidence of student learning, (d) increase the number of students who transfer successfully, (e) prepare students for the workforce, (f) mentor and support new faculty, (g) bring greater diversity to its administration leadership, and (h) develop productive relationships with boards of trustees and other policy makers (Boggs, 2011). The community college had a complex mission to extend educational opportunities under an open-door admissions policy while serving a diverse student population including racial/ethnic minorities, first-generation and low-income students (Cohen \& Brawer, 2003). Ultimately, this charge to serve a variety of stakeholders and multiple missions was the reality of the community college. 
These multiple missions may have played a role in the low retention and graduation rates of community colleges (Dougherty \& Townsend, 2006). According to the National Center for Educational Statistics (NCES), only one out of five students at community colleges obtained their desired degrees in 3 years (NCES, 2012). In turn, student success continued to be a concern for the federal government, state governments, and community colleges themselves. The federal government saw retention as a global issue. For generations, the United States led the world in college degree completion rates, yet ranked 16th in the world in completion rates for 25-34 year olds as of 2012 (American Association of Community Colleges, 2012).

It was projected that by the year 2018 the United States will need to fill 46 million jobs; 30 million of those will require some form of postsecondary education. Based on the current production of workers, the nation will not have enough educated workers (Mullin, 2012). As is evident, it is important for the nation to increase the number of educated workers. In turn, the federal government would benefit from the additional taxes paid by a more educated workforce. State governments would also benefit from the increased number of college graduates. If a state had more graduates and lower dropout rates, it would increase the state's tax revenue (Schneider \& Yin, 2012). For example, it was determined that the economic gain by cutting the number of dropouts in half in Florida, New Jersey, and Arizona alone would gain each state well over $\$ 50$ million annually (Schneider \& Yin, 2012).

Increasing student retention would also be a financial benefit to community colleges (Fike \& Fike, 2008). For example, a community college cannot ignore the hundreds of thousands of dollars to be gained by retaining students from Year 1 to Year 2 of their 
postsecondary educations (Wild \& Ebbers, 2002). Another reason retention is important to an institution is to enable it to sustain academic programs (Fike \& Fike, 2008). Retention is also important to community colleges because each institution needs to measure effectiveness, accountability, and budgetary constraints in this new environment (Wild \& Ebbers, 2002). Additionally, accrediting agencies see retention as an important factor in mandated standards (Strauss \& Volkwein, 2004). Also, the states and accrediting agencies that use student retention as a performance factor force institutions to effectively examine why students leave college (Strauss \& Volkwein, 2004).

The financial factors are not the only variables impacting student retention at the community college level; there are also social factors, because community colleges serve a variety of people within their communities. Moreover, they provide access to nearly half of all minority undergraduate students and more than $40 \%$ of undergraduate students living in poverty (Mullin, 2012). In fact, a study found that $71 \%$ of the general public believes that it is sometimes better to attend a community college first before starting at a four-year institution. Its affordability, open door policy, and localized focus make the community college a viable option to low-income students (Mullin, 2012). Other social benefits to earning a college degree are reduced crime rates, increased charitable giving/community service, increased quality of civic life, social cohesion/appreciation of diversity, and improved ability to adapt to and use technology (ACT, 2004). Moreover, society would benefit from improved health/life expectancy, improved quality of life for children, better consumer decision-making, increased social class, more hobbies, and more leisure activities (ACT, 2004). By the improved quality of life, students would have a better 
opportunity to attend community college and have the ability to earn a degree, which would ultimately increase student retention.

A nationwide study conducted by American Institutes for Research between the academic years 2004-05 and 2008-09 investigating the costs associated with persistence and community college students found that in each academic year studied about one fifth of full-time students who began their studies did not return for a second year as cited in Schneider \& Yin, 2011. These students paid tuition, borrowed money, and changed their lives to pursue degrees they never earned. Spanning the 2004-05 academic year through the 2008-09 academic years, state and local governments provided close to $\$ 3$ billion worth of funding to community colleges to help pay for the educations of full-time, degreeseeking students who did not return for a second year. During these same academic years states spent more than $\$ 240$ million in additional money in student grants to support fulltime, degree-seeking students who did not return to their community colleges for a second year. Meanwhile, the federal government spent $\$ 660$ million in student grants to support full-time students who did not return to their community colleges for a second year. In total, $\$ 4$ billion in federal, state, and local taxpayer dollars in appropriations and student grants went to first-year community college dropouts (Schneider \& Yin, 2011).

Based on all the funding the community college received, it was and continues to be considered a key component of America's system of higher education and must play a central role in fulfilling the nation's effort to increase the education level of its population. Part of the initial appeal of a community college was its low cost; however, based on statistics, the low levels of success were, in fact, costly. It was determined that the nation needs more community college students to graduate. However, continuing to invest more 
money and recruiting more students into the existing system was not the answer (Schneider \& Yin, 2011).

Given the significant governmental investment and persistently low retention rates among community college students, current research needs to be performed to find out why these students dropout. The most recent research on student retention showed that students left colleges due to academic under preparedness, job and family responsibilities, lack of motivation, and individual characteristics (Goldrick-Rab, 2010; Seidman, 2012). Students also left college because of too much partying, not getting involved in campus life, low finances, choosing the wrong majors, signing up for the wrong courses, or being firstgeneration students (Escobedo, 2007; Jarrell, 2004). These reasons for leaving should not be generalized to both two-year and four-year college students. More research needs to be done at the community college level to find out the actual contributors to a lack of persistence.

Most research conducted on student retention focused on students at four-year institutions. As such, there was a limited understanding at the community college level of student retention because of the lack of empirical studies that analyze multicampus data and the important contributions of structural/organizational influences to student outcomes (Strauss \& Volkwein, 2004). Specifically, there was a lack of data and analysis of what happens to community college students and how to make their experiences more productive (Bailey \& Morest, 2006). Most of the research completed at the community college level only used descriptive statistics and not empirical research that takes into account multiple factors. In addition, community colleges did not have the resources to adequately assess the issues on their campuses because the institutional researchers lack the 
knowledge to conduct appropriate research to properly measure the factors influencing student retention (Crisp \& Mina, 2012). Research on student retention at community colleges was not published, widely disseminated, and peer reviewed (Crisp \& Mina, 2012). More research needed to be done about community colleges to bring a wider understanding about community college student retention.

There were a number of prominent retention theories on traditional four-year college students but few for the nontraditional two-year college student. Spady (1970) was the first to propose a widely recognized model for college student dropout. Specifically, Spady proposed a sociological model for the dropout process. The next widely recognized work in retention modeling was Tinto's (1975) student integration model. Tinto's work focused on the students' academic and social integrations, both formal and informal. Another widely used retention model was Astin's (1984) developmental theory of student involvement, which focused on the link between the variables emphasized in traditional pedagogical theories and the learning outcomes desired by the student and the professor. Pascarella's (1985) causal model and Bean's (1980) student attrition model were also used in many retention studies. There was one theory specifically for nontraditional students created by Bean and Metzner (1985). The theory took into account the student background characteristics, including ethnicity and socioeconomic status of nontraditional students.

Numerous studies examined student retention at four-year institutions; yet limited research was done on nontraditional students at two-year colleges. Previous research on community colleges was limited to only descriptive statistics. Most of the research done on retention focused on the traditional-age college student at the four-year college. Pascarella and Terenzini (2005) reviewed 3,000 studies in How College Affects Students and included 
in their review many studies on student retention and completion. However, the newest version of the review was almost 10 years old. Although community colleges attracted more attention within the last two decades, the interest was reflected in published research (Bailey, 2005). Toward this end, Townsend, Donaldson, and Wilson (2005) reviewed articles published in higher education journals between 1990 and 2003 and found that only $8 \%$ of the 2,321 articles even mentioned community colleges.

The lack of studies on retention in community colleges did not result from simple oversight on the part of researchers. Instead, three major challenges limited research on retention at community colleges. First, the national data available on community colleges do not adequately measure community college practices, which were designed to improve retention and completion. Secondly, many researchers used basic statistical research methods, which limited the analysis of the data. Thirdly, research done on community colleges was rarely shared with professional colleagues or presented at national conferences (Bailey, 2005). Most of the research and thinking about student retention was based on student engagement and integration with the college. These concepts were more applicable to residential students than to the community college students who commute to campus. However, researchers were not sure how this fit for commuter students attending four-year institutions (Bailey, 2005). Since there were insufficient national data on institutional practices, most program effectiveness research was based on samples from single institutions.

These types of studies can be difficult to generalize because the effects may be based on particular features of the college being studied (Bailey, 2005). Empirical research needs to be done to better explore available data. In effect, community colleges need to 
develop a culture of evidence. This is how institutional researchers play a vital role and faculty and administrators are fully engaged with data and research about the success of their students, using data to make decisions (Bailey, 2005).

While there was a limit to community college retention research, there was a further limit when discussing the retention of students at community colleges participating in statefunded programs. Specially, the state-funded Educational Opportunity Fund (EOF) program provides academic, career and personal counseling, along with orientation programs, tutoring, advising, and study skills workshops. These types of studies on statefunded programs were limited and almost nonexistent at the community college level. Recently, a preliminary study was published documenting the semester-to-semester retention of community college students at three City University of New York (CUNY) system colleges. It showed that retention increased by 10 percentage points for students who enrolled in college during the second semester (Scrivener, Weiss, Sommo, \& Fresques, 2012). Researching the retention rates of students in EOF programs will give a better understanding of student retention for those participating in a student support services program at community college.

Based on the limited knowledge of community college support programs, student retention, and the renewed interest in educating the American population, there was a need to understand student retention in support programs at the community college level. Most research on student retention used four-year college students as the primary focus; yet, these students were very different from those at community colleges (Braxton \& Lien, 2000; Braxton, Sullivan, \& Johnson, 1997; Rendon, Romero, \& Nora, 2000). 
Consequently, to better understand student retention at the community college level, it was necessary to research it specifically at the source: community college.

To expand on student retention research at the community college level it was necessary to look at specific student support service programs that aimed to increase their student retention. For example, the Educational Opportunity Fund Program (EOF) was established by a northeast state in 1968 to increase the enrollment of minority and disadvantaged students at state colleges and universities. At the conclusion of this research, the EOF program existed at 42 of the public research universities, state colleges and universities, community colleges, and independent colleges within the state of New Jersey. The vision of the program has remained to provide access to higher education for students with educationally and economically disadvantaged backgrounds. The central roles of the program were to increase the diversity of students participating in postsecondary education while preparing citizens for entrance into the state's skilled workforce. As such, EOF aimed to develop partnerships with colleges and universities, elementary and high schools, precollege, along with community-based programs to strengthen the pipeline between each level of education in support of the transition to higher education. The fund supported high-quality programs and educational experiences intended to assist students in persisting to graduation while preparing them with the knowledge, skills, abilities, and values, which are necessary to compete in both a regional and global workplace. Ultimately, the mission of the program was to facilitate the development of a college-educated public that reflects the diversity of the state, by working with all colleges, universities and $\mathrm{K}-12$ educational systems to provide access to higher education for students from disadvantaged backgrounds (State of NJ, n.d.). 
The goal of the program at Allure Community College the pseudo name of the research institution was to provide access to educationally and economically disadvantaged students, to provide supplemental financial aid to reduce the educational costs of attending college, to provide support services in the form of individual or group counseling, tutoring, workshops, and mentoring programs to reduce required developmental course work. As a result, the EOF program was one of the nation's most comprehensive and successful statesupported programs (MCC EOF, 2013); despite this, the success of the EOF program has seldom been published in any peer-reviewed journals.

\section{Purpose Statement}

The purpose of this study was to increase the understanding of key factors that contributed to the retention of community college students who participated in the Educational Opportunity Fund (EOF) program. For study purposes, retention was defined as continual enrollment from first to second semester. Specifically, this study aimed to determine if the retention rate differed among EOF and comparable non-EOF students who exhibited similar characteristics.

\section{Research Questions}

1. What is the distribution of the EOF and non-EOF students in the sample? What are the demographic and academic characteristics of the students in the sample? Are there any differences between the EOF group and the non-EOF comparable group?

2. What is the retention rate among the sample? Are there any differences between the EOF group and the non-EOF comparable group?

3. Controlling for all academic and demographic factors, does participation in the EOF program contribute to a higher retention rate? 
4. What other factors are related to retention among the sample? Are there any differences in these relations between the EOF and the non-EOF comparable groups?

\section{Importance of the Study}

In 2010, President Obama stressed the need to educate the nation's workforce with the goal of graduating five million more Americans from community colleges by 2020 (Burns, 2010). As a result, the community college sector has been recognized as a vital portal for educating the majority of America's workforce (National Center for Educational Statistics, 2012). Specifically, community colleges have played an essential role in providing postsecondary educational opportunities for many low-income, first-generation, minority students who might not otherwise attend college. Another core mission of the community college was to serve underserved and underprepared students (Dassance, 2011). To reach President Obama's goal, community colleges needed to focus on retention. Unfortunately, the studies that have been conducted on student support services programs at community colleges were rare. Toward this end, this study aimed to illuminate the impact of participation in a student support services program on student retention in a community college. Research has shown that demographic variables such as ethnicity, employment status, financial status, and academic ability influenced a student's retention at community college. As such, my hope was that the findings of this study would help administrators at community colleges address the problem of student retention more effectively by determining what differentiates EOF students from non-EOF students in terms of key predictors. Another goal was that the results of this study would provide 
insight into factors that contribute to student retention, thereby enabling institutions to implement intervention strategies so as to ensure student retention.

The following chapter will focus on the major theories regarding student retention and a review of the factors related to said retention. In Chapter 3 the method of data collection and analysis will be discussed. Chapter 4 will review all data collected so as to run descriptive and regression analysis. The final chapter will provide a conclusion on the main findings of the study, policy implications for the research institution, and future research suggestions. 


\section{CHAPTER 2}

\section{LITERATURE REVIEW}

For this chapter, I first provided policy background information on student support services programs geared towards student retention. I then looked at theoretical models that have been used for researching college student retention. Next, I reviewed the relevant factors that have been shown to predict college student retention. Finally, I provided a summary that highlighted the need for student retention research at community colleges.

The purposes of this literature review were: (a) to review the three types of funding related to programs designed to improve student retention; (b) to review the theoretical models that have been used in researching student retention in higher education; (c) to identify the key factors related to student retention, with particular emphasis on statefunded programs designed to help disadvantaged students persist in college; and (d) finally, to discuss the current limitations related to student retention research.

Although community college students were the targeted population of this literature review, research conducted at community colleges was scarce. Rather, the majority of retention research was conducted on four-year college students. Therefore, studies that used the four-year college population were also included in this review. The results were interpreted with caution due to the differences between community college students and their four-year counterparts.

\section{Policy Background}


U.S. student support services programs date back to the 1960s, and these programs varied in the types of services they offered. Nevertheless, the goal of this literature review was to focus on those student support services programs that provide college completion support, in terms of retention, to students from disadvantaged backgrounds. According to the Pell Institute (2009), student support services programs enabled students to successfully begin their college careers, to persist in their studies, and ultimately to earn degrees. These programs offered services that included tutoring, counseling, and remedial instruction (The Pell Institute, 2009). Although the services and funding varied from program to program, the goal was the same: to help students succeed in higher education. In turn, funding sources included, but were not limited to, the federal government, state government, and individual colleges or universities.

Federally funded student support services programs originated in 1964 when President Lyndon Johnson signed the Economic Opportunity Act, and later the Higher Education Act (HEA) of 1965. That legislation was passed to create the Office of Economic Opportunity and the nation's TRIO programs, which were designed specifically to assist students from disadvantaged backgrounds (McElroy \& Armesto, 1998). They were established to provide supplementary academic support to historically underrepresented students (Swail, 2000). After the first reauthorization of HEA in 1968, TRIO's Student Support Services programs, which included Upward Bound, Talent Search, Student Support Services (SSS), Education Opportunities Centers (EOC), the Staff and Leadership Training Authority (SLTA), The Ronald E. McNair Post-Baccalaureate Achievement Program, and Upward Bound Math/Science Program (McElroy \& Armesto, 1998), were established. Understandably, each program had its own focus. The federally 
funded SSS program provided disadvantaged students the opportunity to attend college with assistance in meeting basic college requirements, opportunities for academic development, and motivation to successfully complete postsecondary degrees (McElroy \& Armesto, 1998). The goal of the SSS program was to increase the college retention and graduation rates of all students involved while facilitating their transition from one level of higher education to the next (McElroy \& Armesto, 1998). The services within the SSS programs were diverse and included counseling, tutoring, workshops, labs, cultural events, special services to handicapped students, and instructional courses (Chaney, Muraskin, Cahalan, \& Goodwin, 1998). As of 2005, there were more than 944 federally funded SSS programs; about $51 \%$ were at four-year institutions, and $47 \%$ were at two-year public institutions (Zhang, Chan, Hale, \& Kirshstein, 2005).

State-funded SSS programs are relatively less known, though they have most of the same goals as federally funded SSS programs. Studies found that despite growing efforts by states to improve college success, it is unclear what actions they have taken to help foster college completion (McLendon, Tuchmayer, \& Park, 2010). These state-funded programs, like the federal programs, focused on student success and provided services that were similar to those of the federal programs. These services included, but were not limited to: comprehensive advisement, financial support, tutoring, and counseling (Scrivener et al., 2012; State of NJ, n.d.). The goals of the state programs were to increase the likelihood of students attending, persisting, and graduating from college (State of NJ, n.d.; State of New York, n.d.; Swail, Quinn, Landis, \& Fung, 2012). Since there was not a nationally published study of the state-funded student support services programs as of the conclusion of this research, it was difficult to determine how many exist nationwide. In the 
northeast region, where the focus research institution was located, there were more than 100 programs located in New Jersey and New York amongst the four-year institutions and their two-year counterparts (State of NJ, n.d.; State of New York, n.d.).

Besides the federal and state programs, there were various institution-funded student support services programs. Statistics from Escobedo (2007) stated that these institutional programs are established by the institution, are based on the need of the institution, and include, but are not limited to, student success courses, academic planning, new student orientation, first-year experience, developmental education, advising, learning communities, and bridge courses. Many of these programs were established at the institutions to improve retention, develop students' academic and personal skills, enhance study skills, improve academic planning, increase early registration, increase peer mentoring, and facilitate the completion of developmental courses (Center for Community College Student Engagement, 2005; Escobedo, 2007). They were further designed for a variety of students including, but not limited to, individuals with low-income families who may be first generation, disabled, or from specific racial or ethnic groups (Center for Community College Student Engagement, 2005). In addition, said programs were found to be similar to both the federal and state-funded student support services programs. Though the funding for these student support services programs was different, the goals were the same: to foster students' success, whether that means helping their students gain admittance to college, persist once in college, or helping them to graduate.

The literature indicated a need for a better understanding of the state-funded programs as they relate to or differ from federal and institutional programs. There was too little known about state-level funding aimed toward fostering college completion 
(McLendon et al., 2010), despite the growing efforts in many states to improve college success (Hauptman, 2007). The extent to which states have given college student retention a high priority was not well known (McLendon et al., 2010). The research illuminated student retention as it related to state-funded programs, and provided researchers with a broader understanding of different approaches to increasing student retention.

Theoretical models related to college student retention, which ranged in date from the 1970s to 2004, were reviewed in the next section to give an understanding of past and present factors used in student retention models. Some of the models built on each other, while others were stand alone. Although there were many models on student retention from which to choose, few highlighted the nontraditional students who make up the typical community college, which was a focus of this research.

\section{Defining Student Retention}

Before starting the true purpose of this literature review, it was important to provide an overview on the historical development of retention, as well as to define the term in the context of the current study. Retention is about the student. Meanwhile, the types of students served by colleges and universities have changed over the last decades. It shifted from a small, selective, homogenous group of privileged people to a diverse spectrum of individuals totaling in the millions. As the American population attending college grew, so did the retention issue. Student retention was insignificant decades ago because student demand for higher education and their objective of earning a degree was not a priority. As the student population increased and became more diverse, colleges started paying attention to retention. The interest in keeping students enrolled was general at first but 
became more detailed and multifaceted as campuses started focusing on a more diverse range of students in terms of student ability, preparation, and background (Seidman, 2005).

Additionally, as the needs of campuses changed, retention became a campus-based phenomenon. In effect, specific types of campuses tended to attract different types of students. Seidman (2005) found some highly selective, private institutions that were considered more prestigious recruited and enrolled students more likely to be retained given their familial backgrounds, exposure to the expectations of college, and level of educational preparedness. The roles of faculty and other educators, such as college administrators, also evolved, impacted, and were impacted by retention issues. The growth in number of student affairs administrators, admissions officers, and enrollment management professionals was driven by, and helped develop, retention efforts across the spectrum of American higher education. As of 2005, trends showed retention increasingly recognized as the responsibility of all educators on campus (Seidman, 2005).

Policies and intervention strategies emerged in response to concerns about retention and formed the ways in which retention gained importance. The federal and state government created policies and intervention strategies that impacted student retention and the variety of campus intervention programs. The role of state-level policies has historically played a limited role in student retention; however, by the end of the 20th century and the beginning of the 21 st century, many states implemented accountability systems in which retention was used as a key criterion for success and was often a factor in determining funding for state campuses (Seidman, 2005).

The earliest studies on student mortality, as student retention was originally conceptualized, began in the 1930s. Prior to the 1960s, the study of retention and even of 
higher education was still developing. In the late 1960s, a more logical knowledge base and a combination of existing studies began to emerge, most notably Feldman and Newcomb's (1969) revolutionary work on the impact of college on students. Then came the work of Astin and Spady, which prompted a more intensive study on what came to be known as retention (Seidman, 2005). Building on these works, Vincent Tinto published the most widely used retention model, his "interactionalist model" of student retention, in 1975.

According to Seidman's (2005) study, the conceptualization of retention was not consistent over the years. Various aspects of student departure from college were of great interest to educators and researchers for some time. However, the terminology used to explain this phenomenon changed over time and included terms such as: student mortality, college dropouts, student attrition, college retention, and student persistence (Seidman, 2005).

Along with having distinct terms for student retention, there were also multiple definitions. The most common definition used was the ability of a particular college or university to successfully graduate the students who initially enroll at said institution. To date, there were at least four types of retention: institutional, systemic, major, and courses (Seidman, 2005).

The most basic and easy to understand type of retention was institutional retention. This was the measure of the proportion of students who remain enrolled at the same institution from year to year (Seidman, 2005). The next type of retention was systemic retention, which focused on the student and did not consider the institution in which he/she was enrolled. Using system persistence as a measure of systemic retention, a student who 
left one institution to attend another was considered a persister. Therefore, system persistence accounted for frequent transfers or reenrollments at other campuses, in other states, or in other institutions. While this measure was important to understanding and measuring student success, it required tracking and was both expensive and difficult procedurally (Seidman, 2005). Another type of retention took a more limited view of the topic of student retention by viewing it within a major area of study, discipline, or specific department. For example, a student who declared business as a major, but then switched to another, was retained in an institutional sense yet was lost to the business department. Retention within the major could have been tracked by specific colleges or universities, but was not nationally tracked, and remains difficult to measure (Seidman, 2005). Finally, the smallest unit of analysis with respect to retention concerned course completion. Studying the course level allowed the specific determinations of which courses were not being completed even though a student was retained within the institution. As specific as course retention appeared to be, it was difficult to track, and was not nationally posted or compared (Seidman, 2005).

When discussing retention it was important to understand the aforementioned four types. Nevertheless, within this chapter the focus was on institutional retention because historically it was the most important to students, parents, and stakeholders when evaluating the effectiveness of student success (Seidman, 2005). The focus of this research was on first semester to second semester student retention at community colleges, which was considered one of the most important kinds of retention. Previous studies done found that one out of every three students who entered higher education in a given fall semester did not return for a second year (ACT, 2010a). As of 2012, community colleges had the 
lowest retention rate of all the nation's colleges and universities from first semester to second semester at 55\%, compared to four-year institutions at about $65 \%$ (ACT, 2012). The results of a community college study on student retention by Craig and Ward (2008) concluded that early intervention for disadvantaged students would increase student retention. Many researchers have focused on first-year student retention, and on pinpointing first semester retention as the most important (Barefoot, 2004; Craig, \& Ward, 2008; Kuh, 2009; Porter \& Swing, 2006;). In community college, less than half of students who enrolled each semester returned the next semester (Fralick, 1993). As such, over the last two decades first-year programs were created with the primary focus of increasing retention, to increase student persistence (Barefoot, 2004). First-year seminar courses became nearly a staple in American higher education, with close to $94 \%$ of accredited fouryear colleges and universities offering them (Porter \& Swing, 2006). The first few weeks of the initial semester were considered the most important for colleges and universities for promoting student success and to ultimately improve retention to the next semester (Kuh, 2009).

\section{Theoretical Models of College Student Retention}

To further investigate student retention, this study took an in-depth look at the theories and researchers related to retention. A pioneer in researching student retention was William Spady (1970). His theory stemmed from previous research completed on college dropouts, balance theory, and Durkheim's theory of suicide. Spady proposed the first widely recognized model for college student retention. Spady's model proposed five independent variables (grade performance, intellectual development, normative congruence, friendship support, and social integration). These variables were linked 
indirectly to the dependent variable: drop-out decisions through two intervening variables, satisfaction and institutional commitment (Spady, 1971; Summers, 2003). Spady's model provided a theoretical rationale for looking at both the academic and social systems of the college experience while simultaneously linking precollege experiences and attributes with later social and academic outcomes (Spady, 1971).

Another researcher who played a role in student retention theory was Arnold Van Gennep. Van Gennep's research looked at the passage of an individual from birth to death and from membership in one group or status to another. This correlated to the high school students leaving their friends in high school to meeting their new friends in college. This transition from high school to college was a student moving from one group to a new group. Specifically, Van Gennep's work (1960) helped Vincent Tinto arrive at his theory of student departure by identifying three distinct stages the individual went through: separation, transition, and incorporation (Tinto, 1987).

Emile Durkheim (1950) was another researcher who played a role in the creation of student retention models. Durkheim correlated higher education with the four types of suicide: altruistic, anomic, fatalistic, and egotistical. Altruistic suicide was defined as taking one's life, which might be morally acceptable to the society given the situation. The anomic type was a situation in which a person's normal behaviors were disrupted by upheaval in society (war, plague, looting, rioting, and family dissolutions are some examples). As a result, the person was left without adequate guidelines of how to conduct his/her daily life. In contrast, the fatalistic type was defined as the only way out of a hopeless situation in which any other response would be seen in society as a serious violation of existing norms. Lastly, egotistical was the form of suicide in which the 
individual was unable to become integrated into an established membership within the communities of a society. In a number of respects, these four types of suicide were analogous to higher education. Tinto was able to pull from Durkheim's work on suicideby connecting these works together to eventually create a theoretical framework on student retention. Spady's work on student retention and Van Gennep's work on an individual's passage from birth to life and membership from one group to another also were impacted by it.

As a result, Vincent Tinto's framework for student departure became the most widely recognized and tested theory, which was built from the work done by William Spady (1970), connecting the work of Emile Durkheim (1950) and that of Arnold Van Gennep (1960). Tinto theorized that the process of retention was marked over time by different stages in the passage of students from past forms of association to new forms of membership in the social and intellectual communities of a college. Beyond the transition to college, retention entailed the integration of the individual as a competent member of the social and academic communities of a college. It was the interaction an individual had formally and informally with the academic and social communities on campus and his/her perceptions of those interactions that impacted his/her decision to stay or leave (Tinto, 1987). Tinto believed the cumulative interaction over time of categories of variables that included backgrounds, initial commitments to college study, and interactions with peers and faculty that contributed to both social integration and academic integration. He theorized that students entered colleges or universities with particular characteristics and skills that affected their initial commitments to their educational goals and their institution (Ishler \& Upcraft, 2005). In effect, a student's commitment was increased or decreased 
depending on the quality and quantity of academic and social experiences. If a student had rewarding academic and social experiences, he/she became integrated into the institution. Consequently, Tinto believed that greater integration led to higher retention rates.

Even though the next model, Astin's input-environment-outcome model (year), was not created specifically for student retention, it was used in relevant studies. The model started with the notion that student success was a function of who the student was prior to entering a particular college and what happens after he or she enrolled. It hypothesized that students entered college with a set of characteristics that influenced their views about higher education (Ishler \& Upcraft, 2005). Astin (1984) identified 146 possible input (precollege) variables (e.g., high school grades and admission test scores, race, ethnicity, age, gender, marital status, religious preference, income, parental level of education, and reasons for attending college) he used to assess student retention in an attempt to understand the influence of students' backgrounds and characteristics on their abilities to persist (Ishler \& Upcraft, 2005). In addition, his model identified 192 environmental variables that might influence retention. The variables were organized into eight classifications: institutional characteristics, students' peer group characteristics, faculty characteristics, curriculum, financial aid, major field of choice, place of residence, and student involvement. The final component of Astin's model was outcomes, which focused on the effects of college. These were the students' characteristics after exposure to the environment. Astin listed 82 outcomes, which included: satisfaction with the collegiate environment, academic cognition, career development, academic achievement, and retention (as cited in Ishler \& Upcraft, 2005). Astin's model looked at student success as a 
function of how the student was prior to entering college and what happened after he/she enrolled.

Pascarella (1985) developed a general causal model. In it a student's background/precollege traits and the structural/organizational characteristics of institutions directly impacted the college environment. Pascarella theorized that student precollege traits were correlated with institutional types and that both of these influenced the institutional environment and interactions with agents of socialization, such as faculty members, administrators, and peers. Pascarella suggested that persistence and withdrawal decisions were a function of the interaction of four sets of variables: student background characteristics, institutional factors, informal contact with faculty, and other college experiences. These four variables not only explained changes in student learning and cognitive development, but also shaped the fifth set, "the quality of educational outcomes," which, in turn, explained persistence and withdrawal decisions.

Another model used in student retention research was Bean's (1985) model of student departure, a psychological processes model, which explained the factors contributing to student attrition. The model was an adaptation of an organizational turnover model, which was developed to explain employee turnover in work organizations. The model presumed that students dropped out of college for many of the same reasons that employees left jobs. In Bean's model, attrition factors were based on student demographic variables, student satisfaction with the college environment, and organizational commitments and determinants. External factors and non-cognitive variables, such as family approval and the perceived quality of institution, played the most important roles in retention. 
Bean's model was later modified (Bean \& Metzner, 1985) to account for nontraditional student attrition from two-year and four-year commuter colleges. The model created by Bean and Metzner (1985) was associated with a nontraditional undergraduate student's decision to persist. Since nontraditional students did not have the opportunity to become socially integrated into an institution, a new theory was needed to link the variables that could help explain the retention of nontraditional students. This nontraditional student attrition model was developed from an original one by Bean (1980) and modified to create this new model (Summers, 2003). This nontraditional model, specifically developed for the nontraditional student, recognized the smaller role that social integration played in the retention of nontraditional students. Bean and Metzner identified behaviors as actions shaped by students' attitudes and beliefs that resulted not only from the experience within the institution but from external factors as well, such as the student's financial situation or familial support. The behaviors were based on the perception of institutional quality as well as students' perceptions of their own fits within institutions. The dropout decision was based on four sets of variables: (a) academic performance as measured by grade point averages; (b) intent to leave, which was influenced primarily by psychological outcomes and academic factors; (c) background and defining variables, primarily high school performance and educational goals, and (d) environmental factors, which were expected to have substantial direct effects on withdrawal decisions (Bean \& Metzner, 1985; Summers, 2003). Also included in the model were two forms of interaction between the academic variables and the environmental ones. Environmental variables were important enough to cause a nontraditional student who even had low values for the academic variables to stay in college if his or her values for the environmental variables were in a positive direction. 
In the opposite way, if a student had very high values for academic variables but values for environmental variables were in a negative direction, that student was more likely to drop out (Summers, 2003). The second form of interaction was between the element of academic outcomes and psychological outcomes. Psychological outcomes were important enough to cause a nontraditional student who had poor academic outcomes to stay in college if the psychological outcomes were positive. The reverse of that was the situation in which a student had very positive academic outcomes but negative psychological ones, which may have caused him/her to leave the institution (Summers, 2003). This model had less social integration as it related to a student's decision to persist.

Toward this end, the Cabrera, Castaneda, Nora, and Hengstler's (1992) model of student persistence merged the best elements of the Tinto (1987) student integration model and the Bean (1980) student attrition model (Strauss \& Volkwein, 2004). Both models regarded persistence as the result of a complex set of interactions over time. The two models also argued that precollege characteristics affected how well students subsequently adjusted to their institutions. These models also argued persistence being affected by the successful match between the student and the institution (Cabrera et al., 1992). By incorporating these two models, the Cabrera model more realistically identified attrition variables. It proposed that institutional commitment was directly affected by academic integration, intellectual development, encouragement from significant others, financial aid, financial attitudes, and social integration. Furthermore, the model proposed that precollege academic performance and college grade-point average had indirect effects on institutional commitment. 
More recently, Braxton, Hirschy and McClendon (2011) extended Tinto's model to commuter universities and community colleges. They maintained that Tinto's model did not address the problem of students leaving a community college because the conflicts a commuter college student faced were not the typical experiences of students on residential campuses. Students at commuter colleges faced their obligations to family, work, and academics. Braxton et al. (2011) wanted to build student involvement in the classroom through learning communities. Braxton et al. (2011) believed that analyzing student departures at commuter institutional settings would require constructs of various theoretical orientations: economic, organizational, psychological, and sociological. They also wanted colleges to connect with parents and spouses because significant others had more daily influences on commuter students than on residential students (Braxton et al., 2011). They viewed course convenience relative to time and location as a practical consideration for commuter students, along with developing jobs on campus and providing daycare to ease college, work, and family conflict. As of this research, this model was not tested but stemmed from various studies on student retention.

Based on all past research of student retention, multiple conclusions could have been drawn from attempts to explain college student retention in terms or theories, models, and concepts. Most retention models addressed three variables: background or precollege ability related to the individual students, environmental factors attributed to the student's individual circumstances, and institutional causes related to student retention. The models of Tinto, Astin, Pascarella, Bean, and Cabrera et al. involved more social integration, compared to the two nontraditional models of Bean and Metzner and Braxton et al. 
Although there have been decades of research, at the time of research no single theory existed to thoroughly explain nontraditional student departure (Braxton et al., 2011). The reason for this was the complex nature of student departure (Braxton et al., 2011). Community college students were different from those attending four-year institutions. As such, theoretical models that focused on the social integration of students were less applicable in examining this type of student population. The models of Bean and Metzner and Braxton et al. were geared toward nontraditional students, as these took into account the environmental variables unique to these students.

\section{Factors Predicting Retention}

Based on retention models developed in the past, research revealed factors that influenced student retention: students' integration into the institutions, environmental factors, demographic factors, financial factors, academic factors, academic integration factors, and non-cognitive factors. Consequently, the variables most important for this review of four-year and two-year institutions can be classified into these categories: demographic factors, academic factors, and state-funded program factors. Although this review included both four-year and two-year institutions, the latter was highlighted. Demographic factors

The demographic variables found to predict retention included age, gender, ethnicity/race, and socioeconomic status. These factors were considered important for helping students better understand what they must do to persist and to help institutions learn what they must do to help students persist.

\section{Age}


In any study of college retention, age was a factor. Over the past several decades, the average age of college students increased (Ishler \& Upcraft, 2005). Many studies involving community college students showed that college retention could vary with age. Some researchers found negative relationships between higher age and community college student retention (Brooks-Leonard, 1991; Hagedorn, 2010; Lanni, 1997; Windham, 1995). These studies found that as age increased, student retention decreased significantly. Therefore, younger students were able to persist at a higher rate than their older counterparts. Leppel (2002) also found that age was a predictor of persistence in the study on similarities and differences in the college persistence of men and women. Leppel found that older students had a lower persistence rate than younger ones. Specifically, the study used the 1990 survey of Beginning Postsecondary Students (BPS) conducted by the National Center of Education Statistics (NCES, 2012). Hagedorn (2010) conducted a study of a large community college on the west coast and found that younger students were more likely to persist than older ones. Another study by Nakajima, Dembo, and Mossler (2012) found that age influenced student persistence, but only when age was alone.

Another researcher, Feldman (1993), found that age was a predictor of retention both alone and in competition with other predictors. Older students were more likely to drop out than those ages 20-24. Fike and Fike (2008) analyzed predictors of fall-to-spring and fall-to-fall retention for 9,200 first-time-in-college students who had enrolled in a community college over a four-year period. They determined that age was statistically significant for fall-to-spring retention, but appeared to be of limited practical significance, as it had a very small effect size. Gutierrez and Dantes (2009), who were driven by a desire to document student outcomes at community colleges, decided to develop a practical 
tool to document multiple student outcomes in retention, including graduation, transfer, baccalaureate degree attainment, and successful course completion for 6 years. They concluded, based on their six-year longitudinal model utilizing the institution data, along with National Student Clearinghouse data, earnings data, and a statistical modeling, that older students were more successful than younger students. They attributed the older students' successes to higher rates of successful course completion despite their lower rates of degree and certificate completion.

\section{Gender}

As of 2012, female students made up more than half of college enrollees (NCES, 2012) and tended to persist at higher rates than men (Ishler \& Upcraft, 2005). A study conducted by Wohlgemuh, Whalen, Sullivan, Nading, Shelley, \& Wang (2007) at a fouryear institution confirmed this. Gutierrez and Dantes (2009) had similar results of females having a higher rate of persistence than males at community colleges. In fact, multiple studies prior to 2000 showed a relationship between gender and persistence (Astin, 1993; Astin, Tsui, \& Avalos, 1996; Lewallen, 1993; York, Bollar, \& Schoob, 1993). Feldman (1993) and Voorhees (1987) found that gender played a role in persistence at community colleges yet was not a significant determinant of student retention. Feldman (1993) found that gender related to persistence when tested independently but did not hold up when other factors were included. Voorhees (1987) found a marginal association between gender and persistence; namely, females persisted at a higher rate than males. Equally, a study compiled by Rajasekhara and Hirsch (2000) of 23,000 students at a three-campus community college over a 3-year period found that first to second semester persistence was higher for women than for men. A study by Nippert (2000) using Cooperative Institutional 
Research Program (CIRP) surveys looked at an overall student sample of 4,408 and an institutional sample of 360 two-year colleges. It found gender to be a predictor of student retention. As expected, women were more likely to complete their degrees than men.

A noted researcher in student retention, Astin (1993), found that women had higher completion rates than men when other factors of persistence were taken into account at a four-year institution. Astin et al. (1996) found that women were more likely to complete bachelor's degrees, regardless of the time spent in college. The National Student Clearinghouse Research Center (2012) conducted a 6-year national longitudinal study for a fall 2007 cohort, showing that women had a 6\% higher completion rate than men. Moreover, in a study conducted by Noble, Flynn, Lee, and Hilton (2007), it was found that females were more than twice as likely as males to graduate in 4 years. In 2012, the National Center of Education Statistics published a report on gaps in access to and persistence in higher education by minority males. The report found that across all racial/ethnic groups, for first-time students seeking a bachelor's degree at four-year colleges, females had a higher rate of completion of bachelor's degrees within 6 years than males.

\section{Race/Ethnicity}

Race and ethnicity have been shown to factor in predicting student retention. Chaney et al. (1998) investigated at a four-year college the impact of a student support services program on retention. The specific program studied was a federal TRIO program designed to help disadvantaged students stay in and complete college. Chaney et al. found that Asians and Hispanics had higher retention rates, while Blacks and Native Americans had somewhat lower rates. In the study Feldman (1993) completed to identify predictors of 
attrition for at-risk students, Feldman found that Black students were more likely to drop out than Whites, while minority students showed a higher rate of dropping out than Whites. The study done by Gutierrez and Dantes (2009) found, like Chaney et al. that Asian students were more successful than Black and Hispanic students. In addition, Gutierrez and Dantes (2009) found that White students were more likely to be successful than Black and Hispanic students, which contradicted Chaney et al. study in which he found Hispanic students to have higher retention rates than Blacks. Leppel (2002) also found that Black students have lower retention rates than White students. This finding was also evident in a report published by the National Center of Education Statistics (2012) that showed that Black and Hispanic students had a lower rate of bachelor degree attainment when compared to Whites and Asians. Specifically, Blacks and Hispanics had a 51 and 52\% rate of attainment, respectively, of four-year bachelor's degrees as compared to $73 \%$ and $76 \%$ for White and Asian students, respectively.

Moreover, there have been a number of studies that indicated being a minority student had a negative effect on student retention. Cofer and Somer (2001) found that White students had higher retention rates than minority students when using the National Postsecondary Student Aid Surveys of 1995-96 and 1992-93 for two-year colleges. Hawley and Harris (2005) found that in their study of predominately Black community colleges ( $77 \%$ of the student population was Black), that being Black or Latino was a strong indicator of retention while being Mexican American was a significant indicator of dropping out. Conversely, Voorhees (1987) and Brooks-Leonard (1991), in their studies at a community college, did not find ethnicity to be a predictor of retention.

Socioeconomic status 
In addition to ethnicity being a factor in student retention, researchers have found that socioeconomic status (SES) can also predict student retention (Benbow, Arjmand, \& Walberg, 1991; Braunstein, McGrath, \& Pescatrice, 2001; Conell, Aber, \& Spencer, 1994; Fike \& Fike, 2008; Strauss \& Volkwein, 2004). It appeared that socioeconomic status had a major influence on a student's decision to persist in college (Nakajima et al., 2012). Goldrick-Rab (2010) discovered that university students with a low SES were more likely to leave their institutions, compared to those from privileged backgrounds. Studies conducted at community colleges show similar influences of SES on student persistence. Even when controlling for students' backgrounds (gender, race/ethnicity, and parents' education) along with other factors likely to affect persistence (dependency status, institution type, enrollment delay after high school, enrollment status, amount worked, borrowing, and assistance from parents), U.S. Department of Education (2000), using national datasets, found that low-income students were less likely to persist or earn degrees or certificates.

A study by Walpole (2003) sampled 209 four-year institutions in the United States and more than 12,000 students; it found that individuals from lower SES were less successful than those from higher SES. Garardi (1996) found that when families had incomes of $\$ 12,000$ or more, the likelihood of the student graduating increased. Adelman (2006) conducted a study for the U.S. Department of Education (year) using a national dataset and found that students with lower SESs graduated at a lower rate than those students with higher SESs. Specifically, students' graduation rates were as follows: lowest income graduated at a rate of $35 \%$, middle income graduated at a rate of $55 \%$, and highest income graduated at a 79\% rate. Pascarella and Terenzini (1991) concluded that the best 
predictor of student retention in college was undergraduate grades. Pascarella, Smart, and Ethington (1986) found that for women, the SES had a positively direct effect on degree persistence. Parents with low SES tended to view high school diplomas as the norm; whereas, high SES parents considered a bachelor's or advanced degree as a norm. In addition, Leppel (2002) found a relationship between SES and persistence. The higher a student's SES, the more positive the impact of persistence. Students from a higher SES were more likely to have parents who attended college and were more likely to have access to critical information and financial resources necessary for completing college (GoldrickRab, 2010).

\section{Academic Factors}

Several academic variables, including enrollment status, college placement test, college GPA, and college major were associated with student retention. Research found these factors to be determinants of students persisting in college.

\section{Enrollment status}

In general it was found that full-time, first-year students persisted at a higher rate than part-time enrollees (Ishler \& Upcraft, 2005). Hoachlander, Sikora, Horn, \& Carroll (2003) identified enrollment status as a factor in student retention. Rajasekhara and Hirsch (2000) found that the fall-to-spring retention rate was higher for full-time students, at $75 \%$, compared to 55\% for part-time students. Cofer and Somers (2001), in their study that used a national dataset for two-year colleges, showed that full-time students were more likely to persist than part-time students. Brooks-Leonard (1991) also found enrollment status as a variable related to student retention. Kiser and Price (2008) sampled about 1,000 students at a four-year university and found that students who had more courses were more likely to 
matriculate to their sophomore years. Feldman (1993) identified enrollment status as a predictor of student retention. Part-time students were more likely to drop out than fulltime students. Adelman (2006), who conducted a study for the U.S. Department of Education using a national dataset, found that students who had less than 20 credits at the end of an academic year were less likely to complete degrees. Schmid and Abell (2003) found part-time enrollment, along with other demographic indicators, as risk factors for not completing degrees. In a community college study done in California, researchers investigated the contributors likely to influence a student's decision to drop out or stay in college and found that enrollment status was a factor in student persistence (Nakajima et al., 2012). Students enrolled part-time were more likely to drop out or leave college. Seventy percent of students who did not persist had been enrolled part-time. Twenty-nine percent of students who did not persist were enrolled full-time, which showed that students who enrolled part-time were less likely to persist in college (Nakajima et al., 2012).

\section{College Placement Test}

In multiple studies, there was evidence that precollege academic ability can play a role in student retention (Allen, 1999; Astin, 1993; Pascarella \& Terenzini, 2005; Stage \& Hossler, 2000). These precollege academic factors included high school GPA, standardized tests, and college placement tests. Based on the data available for this study, this literature review only explored college placement tests, since they were linked to college student retention. Other than standardized tests, colleges used their own tests to help determine the entering students' starting academic abilities (Kubala, 2000). Students who took the American College Testing (ACT) and placed above certain scores in math and reading were usually exempt from taking the placement test upon entry to college. 
Similar to standardized tests, the placement test scores were associated with the persistence behavior of students. Schwartz and Washington (1999) concluded from their literature review that although college placement tests became essential elements in college, they did not predict success uniformly across gender and ethnic groups. However, researchers found conflicting results when predicting how students would do on placement tests based on gender or ethnicity. Kubala (2000) found that the higher the students scored on the college placement test, the more likely they were to persist. Hawley and Harris (2005) claimed that the courses the students were placed into based on the college placement test would be a sound predictor of student retention. They proposed that the more developmental courses the students had to complete, the less likely they would be to persist. The developmental courses students needed to take were a direct result of their scores on the placement test. Federal data indicate that $68 \%$ percent of community college students have to enroll in at least one remedial course (Community College Research Center, 2014).

The most discussed developmental course based on research done by Bonham and Boylan (2011) was mathematics. More students require math remedial assistance than with any other subject (Bahr, 2008). A study done by Provasnik and Plantry (2008) found that mathematics was the most common remedial course for community college students (22\%), followed by remedial reading (10\%) and remedial English (8\%). The portion of freshmen enrolled in remedial courses was larger for mathematics than writing ( $22 \%$ vs. $14 \%)$, and it was the smallest for reading (11\%). Based on the National Center for Education Statistics (2000) study entitled Remedial Education and Degree Granting PostSecondary Institutions, mathematics was the developmental course most likely offered by 
colleges and universities, with $72 \%$ reported offering at least one developmental math course (68\% offered developmental writing course and 56\% developmental reading). Few students who begin the remedial math sequence ultimately complete it and achieve collegelevel math competency (Bahr, 2013). In a study of community college students, Garardi (1996) found that reading and writing assessment scores increased the chances of predicting graduation. Similarly, Lanni (1997) discovered that English assessment scores were associated with retention. The results of past studies showed students' placement test scores predicted their college academic performances as well as their persistence decisions. In general, the students who were successful on their college placement tests tended to be successful in college.

\section{College GPA}

Moreover, there was substantial evidence that one of the best predictors of first-year student persistence was his/her first year GPA. Numerous researchers found evidence suggesting that student retention was related to academic performance, as measured by grade point average (Adelman, 2006; Karlen, 2003; Nippert, 2000; Titus, 2006). Xiao (1999) found that second semester GPA was the best predictor of retention, which was a semester difference than Brooks-Leonard (1991) who found that first-term GPA was significant to predicting second semester enrollment. Also, first semester GPA was found to be a predictor of persistence in a study conducted by Adelman (2006) using a national dataset. Kiser and Price (2008) found that first-year GPA at a four-year university significantly predicted persistence. Braunstein, McGrath, and Pescatrice (2000) found in their four-year college study that poorer students, with a first-year GPA in the bottom $25 \%$ 
of their classes, were less likely to persist than those higher income students who were academically more successful.

Research that used institutional and national datasets also showed that a student's GPA was a significant predictor of college retention. An institutional study by Gutierrez and Dantes (2009) found the strongest predictors of student retention were academic characteristics, more than demographics and socioeconomic classes. The national data used in research by Leppel (2002) showed GPA had a positive impact on persistence. Using a national dataset of two-year college data, Cofer and Somers (2001) also showed that students with lower GPAs were less likely to persist. In a study done by Hawley and Harris (2005) on characteristics that impacted persistence among first-year community college students, a student's cumulative GPA was found to be one of the strongest predictors of student persistence. Owens (2003) found that GPA served as an accurate predictor of student persistence in a study conducted at a community college. In two different studies by Cabrera, Nora \& Casteneda $(1992,1993)$, it was found that college academic achievement at community colleges had a direct effect on a student's decision to persist. GPA was found to be a significant factor in both studies, specifically explaining student retention in a study done by Nippert (2000) using Cooperative Institutional Research Program (CIRP) surveys of an overall student sample of 4,408 and an institutional sample of 360 two-year colleges. In a study conducted at a community college in California, Nakajima et al. (2012) found that cumulative GPA was the strongest predictor of student persistence. Students who had higher cumulative GPAs were twice as likely to stay in college.

\section{College Major}


In addition, the major a student selects in college has been shown to increase the probability of attrition (Astin, 1993; Crissman, 2001; Endo \& Harpel, 1982; Rifkin, 1998). For example, Pascarella and Terenzini (2005) found that students majoring in the sciences, engineering, business, and health-related professions were more likely to graduate than similar students in other majors. In a literature review, Daempfle (2003) found that students majoring in mathematics, science, or engineering had lower retention rates in their first years. On the other hand, based on Astin's (1993) research, biology, the humanities, and business were found as majors that had a positive effect on retention. In effect, majors that were more collaborative in nature had a better likelihood of promoting student retention (Crissman, 2001). In a single case study, Nitecki (2011) researched students in paralegal and early childhood programs. Nitecki found that the graduation rates in these programs were higher than the overall college's rate at the community college. Craig and Ward (2008) found that students majoring in engineering, chemistry, business administration, and legal studies had better retention rates than those majoring in art, computer sciences, human services, and office administration. The structure of these programs may have contributed to the increased retention of the students (Craig and Ward, 2008). 


\section{State-Funded Programs}

As stated earlier, although the existence of state-funded student support services programs dated back to the 1960 s, studies were scarce. One of the only studies published for the state-funded Educational Opportunity Fund (EOF) program was a report published in 1992 in The Educational Resources Information Center (ERIC) by Hudson County Community College (HCCC) of New Jersey (Fujita \& Oromaner, 1992). HCCC researched why enrolled students left for reasons other than graduation. A small section of the report discussed the research completed at the institution on the EOF program. In the report, HCCC addressed the previous research that the institution had done on specific cohorts or programs at the institution. In their findings, Fujita and Oromaner (1992) expressed concern that the type of research strategy of choosing only specific programs at the institution to research should be considered a weakness but also a strength. Moreover, the studies did not permit for comparable analysis across the entire college-wide spectrum or for comparable analyses over time (Fujita \& Oromaner, 1992). Although program reviews of the basic skills students and the EOF program had been carried out annually, the institution-wide surveys of enrolled students, former students, and graduates were missing for a few years. For the report, HCCC began an inventory and comparative analysis of their previous research. Students admitted through the program from the fall of 1983 through the fall of 1985 had lower retention rates than regularly admitted students. However, the retention rates appeared to have improved during that period and continued to improve until the report's publication date (Fujita \& Oromaner, 1992).

A more recent study that was still being conducted at the conclusion of my research focused on a state-funded program, the Accelerated Study in Associate Programs (ASAP), 
that was launched in 2007 and operated by The City University of New York (CUNY), the nation's largest public urban university system (Scrivener et al., 2012). ASAP was a multifaceted and long-term program aimed at helping community college students stay in school and graduate. It targeted low-income students who needed one or two developmental courses to build their math, reading, or writing skills and were willing to attend school full time. The study targeted students at three CUNY community colleges (Borough of Manhattan Community College, Kingsborough Community College, and LaGuardia Community College) who met the following eligibility criteria at the point of random assignment: (a) they had family income below $200 \%$ of the federal poverty level and/or were eligible for a Pell grant, (b) needed one or two developmental courses based on CUNY Assessment Tests, (c) were new students or continuing students who had earned 12 or fewer credits, (d) were New York residents, (e) were willing to attend college full-time, and (f) were in an ASAP-eligible major (Scrivener et al., 2012). The students were randomly assigned at two points in time: One cohort of students was assigned just before the spring 2010 semester and the other just before the fall 2010 semester. The total sample size was 896. The study looked at the impact of ASAP versus standard services and courses at the colleges on students' outcomes over a 3-year period. Early findings of the study showed that ASAP had a positive effect on retention. Compared with the control group students, those that participated in ASAP were around 10 percentage points more likely to enroll in any course during the second semester of the study and were 21 percentage points more likely to enroll full time (Scrivener et al., 2012).

To better understand why state-funded programs were a factor in student retention, this section of the literature review focused on unpublished data about state-funded 
programs, which will give greater understanding of the success of the state-funded student support services programs. Specifically, two states that were examined for their student support services programs were New Jersey and New York, because they were in the same region of the country as the research site. On an annual basis, the state-funded programs of New Jersey and New York have to provide a yearly report with a narrative of the major accomplishments of the program as well as student accomplishments over the prior year (State of NJ, 2013; State of NY, 2013). The successes of the New Jersey and New York state-funded programs have only been submitted to the state of New Jersey and New York; they have not been published in any research journals. The state program data for New Jersey and New York only provided a snapshot of the successes of the programs. The state of New Jersey only had student retention information up to 2007 on its website. The chart showed the retention rate over three semesters for state colleges and universities, independent colleges and universities, public research universities, and community colleges. In the fall 2006-2007 academic year, the retention at community colleges was above $55 \%$, the lowest rate compared to the other types of institutions mentioned on the State of New Jersey website. The State of New York fact sheet did not have any identifying information of the date of these data or the types of institutions that were included. It had a 59\% graduation rate and did not give any indication of the retention rate (State of NJ, 2013; State of NY, 2013). Since these data were not published, it was not clear if there was a comparison group or how these figures were determined. As such, it was difficult to determine whether participating in student support services programs led to a higher retention rate in these two states. 
Due to the limited research on state-funded student services programs, the next research reviewed concerned a study on federally funded student support services programs, which was very similar to the state-funded student support services programs. This study by Chaney, Muraskin, Cahalan, and Goodwin (1997) was an assessment report commissioned by the U.S. Department of Education on the "Impact of Student Support Services (SSS)". It was comparable because it provided tutoring, counseling, and remedial instruction to low-income, first-generation college students, which was similar to the services offered and population served within the state-funded program. The goal of the federal program, like the state, was to enable students to successfully begin their college careers, persist in their studies, and ultimately earn degrees (The Pell Institute, 2009). The study looked at both SSS participants and non-SSS participants with similar characteristics. The SSS participants were more likely to remain in higher education, accrue more college credits, and earn higher grade point averages (The Pell Institute, 2009). The study utilized a quasi-experimental design and regression analyses to assess the impact of the SSS program. A total of 5,800 students at 47 institutions were tracked over the course of a 3year period. A comparison group of 2,900 students was utilized with similar demographic and educational profiles to 2,900 first-year SSS participants who had enrolled during the 1991-92 academic year. That study was recently reviewed in a report published by The Pell Institute (2009), since there were not any recent national studies conducted on the federal SSS programs. Based on the limited published research on the effects of statefunded programs on student retention, it was reasonable to move forward with this research. 


\section{Summary}

As was shown, student retention continued to be a significant problem in higher education. This puzzle of student retention was one of the most frequently examined topics in America (Braxton, 2000; McLendon et al., 2010; Pascarella \& Terenzini, 2005). A review of the literature revealed, however, that in previous student retention studies there was a lack of data on community colleges (Bailey \& Morest, 2006; Barnett, 2011; McClenney, Marti, \& Adkins, 2012), a lack of sophisticated data analysis (Karp, 2011; Nakajima et al., 2012; Nippert, 2000; Reason, 2009), and a lack of studies related to the retention of low-income students (Tinto, 2006; Walpole, 2003). These limitations are discussed in more detail below.

First, most of the research conducted on student retention focused on four-year institutions. When looking at all higher education research completed on student retention, $10 \%$ of research studies, at most, focused on community colleges (McClenney et al., 2012). Most research at the community college level was not published, not widely disseminated, and not peer reviewed. In addition, many scholars were not conducting research at community colleges, either because they themselves were not students of community colleges or they had not worked at community colleges. As such, this limited their abilities to interpret or make sense of findings (Seidman, 2012). Although the four-year and twoyear colleges were both institutions of higher education, they had different student populations. Community college students differed in terms of educational goals, demographic backgrounds such as age, ethnicity, socioeconomic status, and academic ability (Bragg, 2001; Center for Community College Student Engagement, 2011). In addition, community colleges were known for their commitments to educating a diverse 
mix of students with widely varying needs (McClenney et al., 2012). Indeed, these students deserved to have research dedicated to their unique characteristics.

Secondly, the methodology that has been used in previous studies was limited. Most studies were methodologically suspect, and because of their weak methods could not provide a strong basis for making policy recommendations (Alfonso, Bailey, \& Scott, 2005). A flaw in previous research showed that a majority of studies investigated a single variable instead of multiple ones (Nakajima et al., 2012). Multivariable research was found to be more useful in the practical setting since, in reality, numerous variables interact with one another to create an overall effect, each with direct and indirect effects on student persistence (Nakajima et al., 2012). When multiple variables were investigated simultaneously, it allowed researchers to examine the interrelationships between them such as they exist in real life (Napoli \& Wortman, 1998). In addition, previous studies had poorly constructed comparison groups or lacked comparison groups, had small sample sizes, low levels of statistical control, and focused on short-term outcomes (Karp, 2011). Also, many studies conducted at community colleges were generally descriptive in nature (Nippert, 2000). A thorough study of retention requires a complicated research design that can clarify not only the direct relationships of each of the variables on retention, but also how the interactions between the variables affect retention (Reason, 2009).

Finally, research was limited when it came to the retention of low-income students and their underrepresentation in past and current research (Berger, 2000). Moreover, they received little attention from researchers (Walpole, 2003) because researchers wanted to focus on mainstream students (Paulsen \& St. John, 2002). The educational experiences of low-income students have long been neglected in the literature (Cabrera, Burkum \& La 
Nasa, 2005). More needs to be known about their experiences in both two-year and fouryear institutions. There was some research available on these students, but not as much as much as there could be (Tinto, 2006). These students needed to be included in research because their background characteristics and life experiences influenced their chances to persist in college (Reason, 2009).

Based on the deficiencies of limited community college data, the need for more analytically sound methods of research, and for further studies of low-income students, my research at the heart of this treatise was necessary. As Vincent Tinto (2006), the aforementioned pioneer in student-retention research, expressed, there was a need for more research on institutional and state actions that enhanced low-income student success in higher education. This study addressed this need by focusing on community college students that participated in a state-funded student support services program, which targeted low-income students in an effort to improve student retention. Lastly, this research provided efficient empirical data by utilizing sophisticated data analysis. Even though student retention was widely studied, there was still much to be explored (Tinto, 2006); my hope was that this study addressed some of this missing information and provided needed research to better understand student retention. 


\section{Research Model}

The proposed model for this study was based on the factors outlined in this chapter. This model integrated the best of the existing theoretical frameworks and included one focal factor (a state-funded EOF program) based on the focus of this research. As illustrated in Figure 1, the major constructs contained in this model included: demographic factors (age, gender, ethnicity, and race), academic factors (college placement test, GPA, and college major), and a state-funded program (EOF). The theoretical models of Tinto (1975), Astin (1984), Bean (1985), Bean and Metzner (1985), Pascarella (1985), Cabrera et al. (1992), and Braxton et al. (2011) all contributed to the research model created for this study. Tinto's model was related to this model because of the demographic and academic factors. However, it also related to the state-funded program because Tinto's model discussed the informal and formal integration the individual has with the college, which directly correlates to the EOF program. The EOF students have direct contact with the college community through academic and social interaction coordinated by the EOF program. All the models except Bean and Metzner (1985) included social integration. While that was also in Tinto's model, the model of Braxton et al. (2011) also incorporated the internal campus environment, which could have been seen as the state-funded program variable, which would fulfill the social integration described in Tinto's model. Astin's (1984) theoretical model looked at student success, namely how the student was prior to entering college and what happened after he/she enrolled. A student's background characteristics before enrolling impacts his/her decision to stay or leave college. These characteristics were also incorporated in the models of Tinto (1975), Bean (1985), Bean 
and Metzner (1985), Pascarella (1985), Cabrera, Nora et al. (1992), and Braxton et al. (2011) and were included in the model created for this study.

All of the theoretical models covered in this literature review incorporated the student background characteristics as predictors of retention. Those background characteristics included demographic, academic, and financial. Although the financial factor was not highlighted in the model, it was incorporated in the state-funded program variable. All of the students participating in the EOF program were low income. Also covered in the theoretical models in this literature review were the academic factors that contributed to retention including GPA, college placement test, and college major. The models outlined how these academic factors play a role in retention. All of the variables in the created model impact student retention.

Lastly, the created model (Figure 1) for this retention research was based on the theoretical models and on previous research conducted on student retention. It provided a good representation of the variables researched to predict student retention. Although not all variables discussed in the theoretical models from this literature review were used because of the limited institutional data, those that were highlighted have been proven to be predictors of student retention. 
Figure 1. Student Retention Model

\begin{aligned} \hline Demographic Factors \\ - Age \\ - Gender \\ Ethnicity/Race \end{aligned}
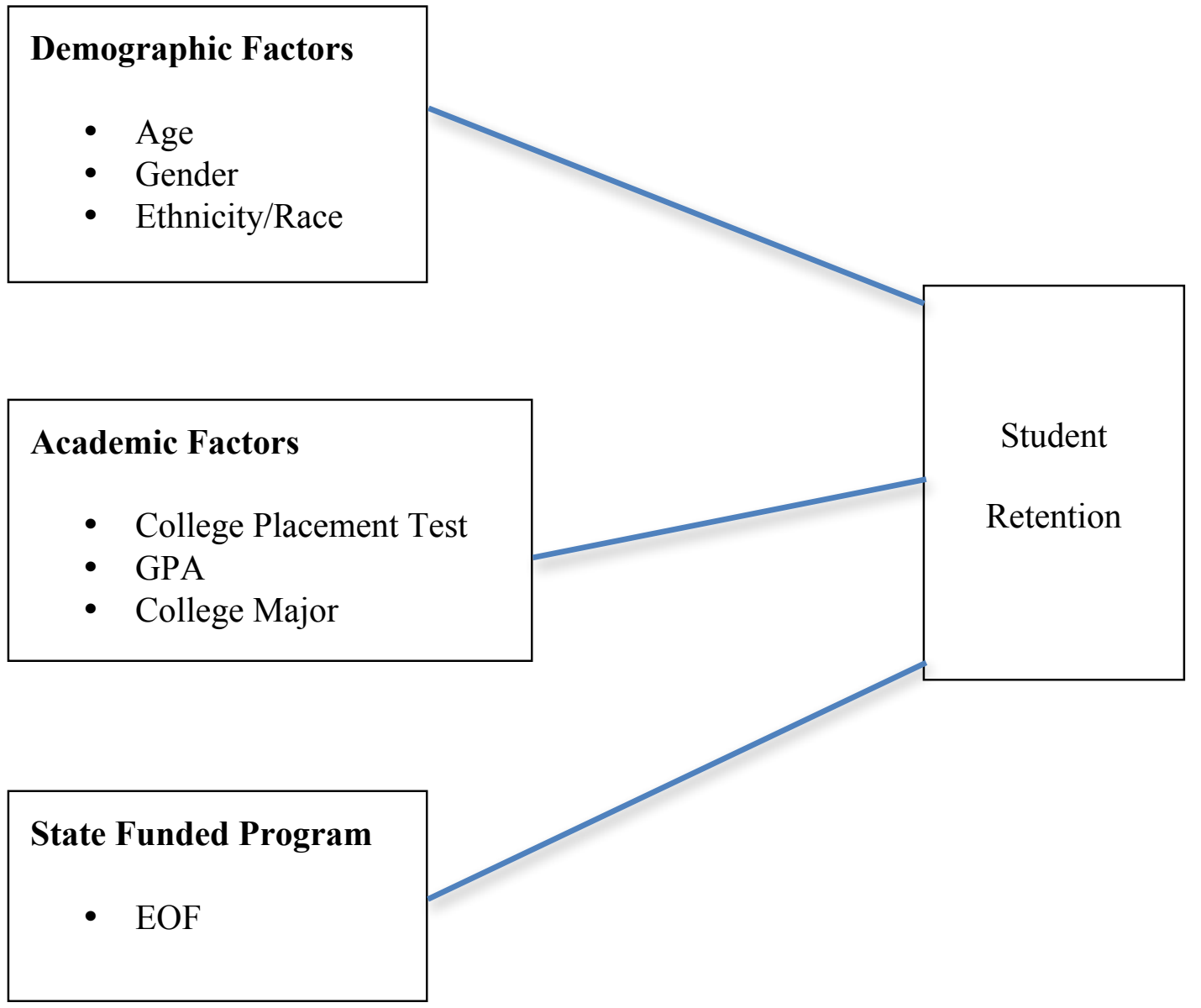


\section{CHAPTER 3}

\section{METHODS}

\section{Research Overview}

The purpose of the study was to understand how EOF and other factors are related to the retention of community college students. Specifically, this study aimed to determine if the retention rate differed between EOF and non-EOF students with similar characteristics, controlling for all other factors. Variables in the model included demographic factors such as ethnicity/race, age, gender, academic performance, college placement test, GPA, college major, and a state-funded program, EOF.

\section{Research Questions}

The following research questions guided this study:

1. What is the distribution of the EOF and non-EOF students in the sample? What are the demographic and academic characteristics of the students in the sample? Are there any differences between the EOF group and the non-EOF comparable group?

2. What is the retention rate among the sample? Are there any differences between the EOF group and the non-EOF comparable group?

3. Controlling for all academic and demographic factors, does participation in the EOF program contribute to a higher retention rate?

4. What other factors are related to retention among the sample? Are there any differences in these relations between the EOF and the non-EOF comparable groups?

\section{Research Design}


The purpose of this research was to understand how the EOF program and other factors correlate to the student retention of community college students. This study looked to determine if students participating in the EOF program have a higher retention rate than non-EOF comparable students. Furthermore, this study investigated the factors that relate to retention between the two groups and any differences in the factors across the EOF and non-EOF comparable groups.

\section{Hypothesis}

This study hypothesized that participation in the EOF program will impact student retention positively. The rationale on which this hypothesis was made was based on theories and previous research. Theoretically, the models of Tinto (1975), Astin (1984), Bean (1985), Pascarella (1985), Cabrera, Nora et al. (1992), and Braxton et al. (2011) that were reviewed in Chapter 2 gave a clear indication that students' interactions on campus have a direct effect on their likelihoods to stay at their institutions. Ultimately, the models showed that the more students interact (academically or socially) on campus or are integrated into the campus, the more likely they are to persist, which means they will have a higher retention rate than those who do not have a direct link to the campus. As it related to this research, the EOF program is believed to be that direct link to the campus.

In addition, research on student support services programs indicated that students participating in a program have a better retention rate than those who do not (Center for Community College Student Engagement, 2005; Cho \& Karp, 2013; The Pell Institute, 2009; Scriverner, Summo, \& Fresques, 2012; Zeidenberg, Jenkins, \& Calcagno, 2007). These programs have been shown to increase the likelihood of a student's persistence in higher education. These programs have also been shown to improve retention, develop a 
student's academic and personal skills, enhance study skills, improve academic planning, increase early registration, foster peer mentoring and facilitate graduation (Center for Community College Student Engagement, 2005; Escobedo, 2007). They were designed to help students succeed in college, persist, and ultimately graduate.

\section{Site}

My research was conducted at Allure Community College (ACC) the pseudonym for research institution, located in the northeastern United States, in a state with a population of over eight million. The median household income from 2008-2012 was $\$ 71,637$ while the percentage of inhabitants below poverty level was close to $10 \%$. Also, the percentage of residents who achieved a bachelor's degree or higher and were 25 or older between 2008 and 2012 was $35 \%$. The race/ethnicity make up of the state was as follows: 58\% White, 14\% Black, 9\% Asian, 18\% Hispanic, and 1\% for two or more races. There were 19 community colleges, 10 public four-year institutions, and 14 private fouryear institutions in the state. Lastly, this state information was necessary for gaining a better understanding of where Allure Community College fits into its regional demographics.

The college was founded in 1964. The college's mission was to provide access to an affordable, quality education for diverse students and to promote lifelong learning opportunities in order to strengthen the economic, social, and cultural life of the community. The college's vision was to put learning first and to measure success only by the performances and positive outcomes of its students. The Middle States Commission on Higher Education accredited Allure Community College. As of 2012, ACC enrolled close to 13,000 degree-seeking students, but started in the 1960 s with about 1,300 students. At 
the time, $56 \%$ attended full time, while $44 \%$ attended part time. These enrollments fluctuated from year to year, but were close approximations. The college also enrolled over 10,000 non-credit students. Although ACC had a large student population in the state in which it is located, it had a 24:1 student to faculty ratio for credit-bearing students. In addition, ACC maintained 162 tenured faculty as of 2012. The college had an array of degrees and certificates, ranging from: accounting and nursing to criminal justice, baking and pastry arts, to name a few. It also offered over 100 degree and certificate programs. Although ACC was a community college, it did have selective programs in nursing, dental hygiene, radiographic education, medical laboratory technology and respiratory care. These programs usually attracted close to 1,200 applications annually for only 175 spots. Of all the fields, some of the most popular were liberal arts, business, accounting and legal studies, protective services, and health technology.

The overall ACC student demographic characteristics included 52\% female and $48 \%$ male. This distribution of female and male was consistent within the past 10 years. The population consisted of 33\% White, 12\% Black, 11\% Asian and 25\% Hispanic, 2\% Native American or Pacific Islander, 3\% for two or more races, and 12\% unknown. The average age of students attending ACC was 23 years old. Over $80 \%$ of students received some form of financial aid. Close to $90 \%$ of all students attending ACC were from the state and county in which the college was located. There were also two neighboring community colleges located in different counties bordering ACC, which students could also attend.

The institution selected for this study on student retention was targeted for a number of reasons. First, improving the retention of students had been a priority for its upper 
administration due to the low rate of degree completion. Ever since the college opened, it had only graduated a little over 51,000 students. Secondly, the EOF program has been in existence at this college since 1968. Thirdly, the student population was large and diverse enough to provide a reasonable sample size for both the EOF group and the non-EOF comparable group. Lastly, the institution was willing to share extensive institutional data.

In addition to the data provided by the institution, The Integrated Postsecondary Education Data System (IPEDS) data for Fall 2012 gave a comprehensive look at first-time undergraduate students at all public institutions in the state where ACC is located. IPEDS showed ACC having a retention rate of $66 \%$ for first-time, full-time students compared to $71 \%$ for all four-year and $62 \%$ two-year public institutions. ACC ranked seventh out of the 19 community colleges in first-time, full-time undergraduate retention rate within the state. The part-time retention rate was $48 \%$, compared to the overall average of all community colleges in its state, which was at $42 \%$.

\section{Sample}

Given the focus of the study on first-year retention and the limited sample size for EOF students in one academic year, the sample for this study included five cohorts of ACC first-time freshman students enrolled between the 2008 and 2013 academic years, using the fall semesters as the initial start terms. The sample was divided into the Educational Opportunity Fund (EOF) group, which included first-time, freshman students who participated in the EOF Program, and the other group, which included first-time, freshman non-EOF students who were comparable to the EOF group in terms of income qualification. 
To determine a student's eligibility for the EOF program, he/she must meet the state eligibility criteria: (a) must demonstrate an educationally and economically disadvantaged background, (b) must be an in-state resident for 12 consecutive months prior to receiving the award, (c) must apply and be accepted to a participating in a state college or university, (d) must meet the academic criteria as set by the institution of choice, (e) must file a Free Application for Federal Student Aid (FAFSA), and (f) his/her gross income and household size must fall within the set state guidelines of the specific academic year he/she is applying for acceptance. Before discussing how I created the non-EOF comparison group, it is important to understand the context of the program eligibility criteria a little better. ACC was an open-door institution, and more than $90 \%$ of its students were residents of the state where it is located. Also, more than $80 \%$ of students enrolled at ACC applied for the FAFSA. Thus, the income characteristic was the most important factor in their being selected to the EOF program. However, not all students who qualified based on income were chosen because the program functioned on a "first come, first served" basis and had a limited number of spots (100-150 seats) available each year. In sum, the comparison nonEOF group was held to the same gross income criteria as students selected into the EOF program, since this was the most critical factor for meeting the EOF program eligibility criteria.

As mentioned previously, the EOF program provided academic, career, and personal counseling, along with orientation programs, tutoring, advising, and study skills workshops. The goal of the EOF program was to provide access and financial support to disadvantaged students and to improve student success as measured by student retention and graduation rates. The program also looked to support students who have academic 
deficiencies. Finally, the program provided individual and group counseling to help students achieve self-actualization and self-motivation.

Based on the literature review and proposed model, this study included the following variables: race and ethnicity (self-reported on admissions applications), age (at the start of the first semester, birth dates as self-reported on admissions applications), gender (as self-reported on admissions applications), college placement test (as entered by the testing center after students take tests), college majors (as self-reported on admissions applications at the start of the first semester), first semester GPA (calculated by the student information system based on final grades), and state-funded program (determined by institutional researcher based on financial aid award of EOF grant).

\section{Data Collection}

The institutional research office provided ACC student data. This quantitative study analyzed data from the ACC student information system for the enrollment period beginning with the fall of 2008 until the spring of 2013 academic years. Multiple years were selected to obtain a larger sample of EOF students. Each fall the EOF program admitted close to 100 students, and based on this enrollment pattern, the need for more than one EOF cohort was necessary. A larger sample size was chosen to increase the confidence that the study results were representative.

To obtain data for this study, two IRB applications were filed. One was with the Office of Institutional Research at ACC and the other with Seton Hall University. The IRB was completed for permission to use preexisting data for the purposes of this study. This study relied on historical data maintained by ACC's Institutional Research Office. Student identifiers were removed prior to the data being provided. Although the data resided in the 
student information system, before these data were on the system they came from multiple sources. The offices involved in entering these data that were used in this study were: admissions, testing center, financial aid, EOF, and registrar. They were responsible for these data in different ways, and how the data got into the student information system was different for each office. For example, the admissions office had a process to import the application data into the student information system. Whereas, the testing center imported the data or manually entered it into the student information system based on the number of test scores at the time of entry. Lastly, the financial aid office imported student information into the student information system, but the director was responsible for creating an automated process that would automatically award students based on information in the student information system. Students could be awarded using the automated process but could also be manually entered depending on their circumstances. The EOF office was responsible for giving all EOF student names and award amounts to the financial aid office so that this information could be manually entered into the student information system. The registrar's office was responsible for creating the process that allowed professors to manually enter their grades into an outside system, which then automatically updated the student information system. The registrar's office had the responsibility of overseeing the GPAs that were automatically generated by the student information system. If a professor could not enter grades in the outside system, the registrar's office had to manually enter them directly into the student information system.

The following explains how all the factors in the study were entered in the student information system. The demographic factors of age, gender, and ethnicity/race were pulled from the student reported information recorded on their admissions applications, 
which were then imported into the student information system. In addition, the socioeconomic status information came from the student's FAFSA, which was pulled from the Institutional Student Information Record (ISIR) by the financial aid department, then imported into the student information system. Information about college majors was pulled from student reported information on their admissions applications, which was then imported into the student information system. Meanwhile, the college placement test score was imported or manually entered into the student information system by the testing center after students take the test. Enrollment status was based on the number of credits the student was enrolled first-semester. The GPA was calculated by the student information system based on the grades manually entered by the professor for each course the students took during the first semester. The state-funded EOF program was recoded by the institutional researcher based on the EOF grant awarded by the financial aid office on the student information system. Specifically, the financial aid office worked closely with the EOF office to determine which students were EOF eligible and should be awarded the EOF grant. At that point, financial aid personnel, once EOF students were identified, manually entered the EOF award into the student information system. Students who were coded with the EOF award were recoded as EOF on the data file by the institutional researcher. Those representing the comparison non-EOF group were determined by the following criteria: selecting students in the start term cohort years $(2008,2009,2010,2011$, and 2012), and meeting the EOF gross income and household size. I extracted pertinent data using this criteria based on the fall semesters of the five cohort years $(2008,2009,2010,2011$, and 2012) to determine the non-EOF comparable group. I then recoded this group as non-EOF.

\section{Model Specification}




\section{Outcome Variable}

The outcome variable in this study was a dichotomous one that indicated whether or not students leave the institution without enrolling for the second semester. The institutional data provided by ACC allowed for this information because enrollment information was tracked. Therefore, the institutional data made it possible to define student retention at the institutional level. More specifically, this outcome variable, which was termed retained, was derived from the enrollment of the student during the second semester.

For students who failed to enroll during the second semester, the outcome variable was coded as $0=$ not retained for the next semester. For students who remained enrolled at the institution for the second semester, the outcome variable was coded as $1=$ retained for next semester.

Independent Variables

Demographic background factors

- Age (categorical variable measuring age as of the start term. As a non-linear relationship between age and retention was assumed, this variable was recoded into the following age groups: $18-23$ and 24 and higher).

- Gender (categorical variable indicating student gender. In the current study, it was recoded into a dichotomous variable with female as the reference group).

- Race/Ethnicity (categorical variable measuring student race/ethnicity. White students were treated as the reference group).

Academic factors 
- College placement test (continuous variable measuring college placement test scores in essay writing, reading comprehension, elementary algebra and arithmetic; $0=$ developmental course $(\mathrm{s})$ needed while $1=$ no developmental course(s) needed).

- Grade point average in college (continuous variable measuring first semester GPA in college as reported by the institution).

- Major (categorical variable representing student's major during start term. The original variable was composed of close to 100 college majors, which was then recoded into 10 categories including humanities, social sciences, life sciences, natural/hard sciences, engineering, education, business, health, technology, and uncodable).

State-funded program factor

- EOF (Referred to a categorical variable indicating student participation in EOF. In the current study, it was recoded into a dichotomous variable where $1=\mathrm{EOF}$ and 0 $=$ non-EOF).

Most of the independent variables included were binary because they were categorical in nature (i.e., race/ethnicity, gender, major, and state-funded program). Age was separated within these two groups because financial aid eligibility and awards stated that a student was not considered independent (an adult) until he/she is 24 years old. This grouping provided a clear indication of the younger students. The college placement test variable was reduced from four categories to two based on a literature review of students either placing into developmental courses or not.

Attempts were made to reduce the number of categories of the college major variable. Similar disciplines were combined and making them into categories combined 
majors. Specifically, the categories used based on the literature review were: social sciences and humanities, science, business, technology, and undeclared.

Another variable considered for recoding was race/ethnicity because of the number of categories identified within this dataset. In turn, race/ethnicity was reduced from eight to five categories. The variable was recoded using dummy variables.

\section{Data Analysis}

The study utilized the Statistical Package for the Social Sciences (SPSS Version 22) software program for quantitative analysis on community college students. To identify the non-EOF comparison group, I selected five freshmen cohorts within the enrollment period Fall 2008 - Spring 2013 using the EOF income eligibility scale, which was used as the main criterion when selecting EOF students. Although the EOF criteria said that students

must demonstrate an educationally and economically disadvantaged background, ACC was a community college in which all applicants are accepted; there was not an academic requirement to be admitted to the college.

Since institutional data were used for this research, there were several advantages and disadvantages when using this type of data. Two of the disadvantages were that randomization was not as strong, and a control group could not be developed. Some of the advantages were: the cost was cheaper; the sample size was larger, and study was conducted more quickly.

In descriptive analysis, the two groups, EOF and non-EOF comparison, were analyzed in terms of their characteristics. Participants of the EOF program had a financial aid package that included an EOF grant versus the non-EOF students who had a financial aid package that did not include an EOF grant. Another analysis was conducted to 
compare the retention rates of EOF students versus non-EOF students at the end of the first term.

The study employed logistic regression analysis to determine whether and if EOF affected freshmen students' retention, controlling for all other factors. The study investigated the two groups of EOF and non-EOF students to determine if there were any differences, whether participation in the EOF program was related to retention, whether other factors were related to retention, and whether those effects differed between the two groups.

Logistic regression was selected as the best type of analysis because the technique allowed for the examination of many independent variables and their strength of influence on a binary dependent variable, which was retained to next semester or not retained to next semester (Creswell, 2005). Logistic regression analysis was a suitable technique for studying students leaving college because of the dichotomous nature of retention as the dependent variable (Tinto, 1975).

The goal of logistic regression was to identify the best linear combination of predictors that maximizes the likelihood of explaining the observed data. Though logistic regression did not make any distributional assumptions for the independent variables and did not require homogeneity of variance within groups, it assumed that: (a) the independent variables were free from measurement error, (b) observations were independent, and (c) none of the independent variables were linear functions of the others. When the assumptions of logistic regression were sufficiently met, the parameters based upon the maximum likelihood method of estimation remained unbiased (Sharma, 1995). 
The first step in data analysis was to clean the dataset. The second step was recoding the independent variables. The third step was running descriptive statistics of the entire sample. Descriptive analysis methods such as frequencies, means, and cross tabulations were employed. Next came logistic regression for the entire sample to find the effects of EOF. Afterward, I ran descriptive statistics for the subgroups of EOF and nonEOF. Finally, I ran logistic regression for the subgroups EOF and non-EOF to determine what key factors helped to predict retention in each group.

\section{Limitations}

One limitation to this study was that it did not lend itself to investigating academic integration or non-cognitive factors related to student retention. Academic integration was one of the most widely studied factors related to student retention. Many student retention models indicated the influence of students' engagement in their college communities as predictors (Astin, 1993; Bean \& Metzner, 1985; Cabrera et al., 1993; Grosset, 1991; Pascarella, 1985; Tinto, 1987). Along with academic integration being found as a factor in student retention, multiple non-cognitive factors were found to be predictors of student retention. These ranged from motivational effect (Allen, 1999; Braxton et al., 2011), educational objectives (Bers \& Smith, 1991; Brooks-Leonard, 1991), intent to enroll (Bers \& Smith, 1991), institutional commitment (Braxton et al., 2011; Strauss \& Volkwein, 2004), self-efficacy (Braxton et al., 2011), support from significant others (Braxton et al., 2011; Cabrera et al., 1992), financial attitudes (Cabrera et al., 1992), academic integration (Halpin, 1990; Napoli \& Wortman, 1998; Nora, 1990), length of time students planned to spend at their colleges (Hawley \& Harris, 2005), student engagement in educationally purposeful activities (Kuh, 2009, social integration (Napoli \& Wortman, 1998; Nora, 
1990), study patterns (Schmid \& Abell, 2003), involvement in school activities (Schmid \& Abell, 2003), purpose (Voorhees, 1987), external environment, goal commitment, expected student/college fit (Webb, 1989) to intent to persist (Cabrera et al., 1992, 1993; Voorhees, 1987). Although academic integration and non-cognitive factors demonstrated an impact on student retention, these factors were not included in this study. They could not be because the institutional data available for this study did not include academic integration and non-cognitive factors. Nevertheless, based on previous research, not including these two factors may have been a limitation of this study.

Another limitation concerned researching a single institution. Previous student retention studies indicated that doing student retention studies at only one institution was a limitation (Kiser \& Price, 2008; Leppel, 2002; Nguyen, Hays, \& Wetstein, 2010; Reason, 2009; Strauss \& Volkwein, 2004). When a study was only conducted at a single institution, there was only focus on whether the student continued at that particular institution and not whether he/she ultimately graduated from another. As such, I determined that multisite research needed to be conducted to allow for richer data analysis. Ultimately, multicampus data will provide a comprehensive analysis on student retention (Leppel, 2002; Nguyen et al., 2010; Reason, 2009; Strauss \& Volkwein, 2004). Since this was a single institution study, the generalizability across institutions may have been limited.

The final limitation was selection bias. The EOF program was essentially voluntary. Students were not admitted to the program unless they applied and met its criteria. Consequently, the motivation of the student could be controlled in this study since selection bias was a limitation in other student retention studies (Miller, Binder, Harris, \& 
Krause, 2011; Nguyen et al., 2010; Noble, Flynn, Lee, \& Hilton, 2007). The students who were selected to the EOF program were the ones who wanted to be a part of it. As a result, they got their information in as quickly as possible because there were limited spots, plus the program took students on a first come, first served basis as long as they met the income eligibility. Those students who were less motivated may have taken longer to turn in their information, which may have resulted in their not gaining a spot in the EOF program. Such a self-selection issue might have brought bias to the results of the EOF program's effects on student retention. 


\section{CHAPTER 4}

\section{RESULTS}

The purpose of this study was to determine if the retention rate differs among EOF and non-EOF students who exhibit similar family income and house hold size characteristics. Using matched samples of EOF and qualified non-EOF students, a quantitative study using logistic regression was conducted to analyze the relationship among demographic factors, academic factors and a state-funded program and its ability to distinguish between students who were retained or not retained. The site of this study was a community college located in the northeastern United States.

The research was conducted in four steps. The first step was to prepare the data for analysis. The data were cleaned, and all cases with missing information were removed. Next, preliminary tests were run including descriptive statistics. These tests were run on all three groups: whole group, EOF group, and non-EOF group. The third step was to streamline the number of predictors. Finally, logistic regression was run for the three groups to analyze the data.

This chapter was divided into two main sections: descriptive statistics and logistic regression results. The first section outlines a presentation of descriptive statistics for all variables used in the analysis. The variables are then separated into categorical, continuous, and dependent variables, looking at the frequency, percent, mean, and standard deviation. A cross tabulation was also run with all predictor variables and retention. The second section covered the three logistic regression models for the whole sample, EOF, and non-EOF samples. 


\section{Descriptive Analysis}

\section{Categorical Variables}

Table 1 presents all the categorical variables used in logistic regression. Table 2 summarizes the continuous variable. Table 3 indicates the number of students in the EOF and non-EOF groups who were retained.

Descriptive statistics for the EOF and non-EOF samples are provided in Table 1. Students were predominately younger (90\%) in both groups. Both groups had close to the same percentage of males at $48 \%$ versus females at $52 \%$. The EOF sample had more students placed into developmental courses than the non-EOF sample. EOF students were placed into essay, reading, and math at $57 \%, 71 \%$ and $73 \%$ respectively versus non-EOF at $46 \%, 58 \%$ and $65 \%$ respectively.

Both samples had similar distributions of students for college major and race/ethnicity. For both groups social science and humanities had the highest percentage of students, $49 \%$ for EOF group and $48 \%$ for non-EOF group. The other majors had the following distribution for science, technology, and undeclared: EOF group, 19\%, 14\%, and $2 \%$ compared to the non-EOF group, $19 \%, 11 \%$, and $4 \%$.

The demographic and academic characteristics that had differences in distributions across the two groups included race/ethnicity and developmental courses. In both groups, Black and White students were the two races that were the most dissimilar. Black students represented $24 \%$ in the EOF sample and only $15 \%$ in the non-EOF sample. White students represented only $15 \%$ in the EOF sample and $30 \%$ in the non-EOF sample. More EOF students were placed into developmental courses than non-EOF students. The EOF group had the highest placement into mathematics at 73\%. Next, the reading developmental 
course had the biggest difference: $71 \%$ for the EOF sample and $58 \%$ of the non-EOF sample. Essay developmental was the most similar: the EOF group at 57\% compared to $46 \%$ for the non-EOF group.

\section{Continuous Variable}

Next, in Table 2, the continuous variable, first semester GPA, shows the difference between the two groups. The EOF group had a slightly higher mean GPA than the nonEOF group. The mean GPA for the EOF group was 2.09 and the non-EOF group was 1.91.

\section{Dependent Variable}

Table 3 shows the dependent variable retained. The EOF group had a larger percentage of students retained than the non-EOF group. EOF had $91 \%$ of students retained compared to $85 \%$ for the non-EOF group. 
Table 1

Categorical Variables

\begin{tabular}{lcc}
\hline Variable & EOF $(\mathrm{N}=570)$ & Non-EOF \\
(6,535) & & \\
\hline Younger & $89 \%$ & $90 \%$ \\
Male & $48 \%$ & $48 \%$ \\
Asian & $12 \%$ & $12 \%$ \\
Black & $24 \%$ & $15 \%$ \\
Hispanic & $33 \%$ & $31 \%$ \\
Other race/ethnicity & $15 \%$ & $12 \%$ \\
White & $15 \%$ & $30 \%$ \\
Cohort1 & $20 \%$ & $19 \%$ \\
Cohort2 & $19 \%$ & $22 \%$ \\
Cohort3 & $23 \%$ & $20 \%$ \\
Cohort4 & $22 \%$ & $21 \%$ \\
Cohort51 & $7 \%$ & $20 \%$ \\
Essay_Dev & $57 \%$ & $46 \%$ \\
Read_Dev & $71 \%$ & $58 \%$ \\
Math_Dev & $73 \%$ & $65 \%$ \\
Business & $16 \%$ & $7 \%$ \\
Science & $19 \%$ & $19 \%$ \\
Social Science \& & & \\
humanities & $49 \%$ & $48 \%$ \\
Technology & $14 \%$ & $11 \%$ \\
Undeclared & $2 \%$ & $4 \%$ \\
\hline & & \\
\hline
\end{tabular}

Table 2

Continuous Variable

\begin{tabular}{lcccc}
\hline Variable & \multicolumn{2}{c}{ EOF $(\mathrm{N}=570)$} & \multicolumn{2}{c}{ Non-EOF (6,535) } \\
& Mean & Std. Deviation & Mean & Std. Deviation \\
\hline First Semester GPA & 2.093 & 1.425 & 1.908 & 1.482 \\
& & & & \\
\hline
\end{tabular}


Table 3

Dependent Variable

\begin{tabular}{lcc}
\hline & & Retained \\
& Frequency & Percent \\
\hline EOF & 518 & \\
Non-EOF & 5534 & $91 \%$ \\
& & $85 \%$ \\
\hline
\end{tabular}

\section{Cross Tabulations for Student Characteristics and Retention}

Finally, the descriptive analyses provided information about the cross tabulation of student demographic and academic characteristics with retention for all three samples. Tables 4,5 , and 6 show the comparisons of retention after the first semester using the independent variables for the whole sample, EOF, and comparable non-EOF samples. Within the three samples the students who were younger, female, and Asian were more likely to be retained from first semester to second semester.

Younger students who were age 23 or younger were retained at $86 \%$ for the whole sample, $91 \%$ for the EOF sample, and $86 \%$ for the comparable non-EOF sample. Female students had a higher rate of retention than their male counterparts. Males in all groups had lower percentage of retention than females. Males were retained at $89 \%$ for the EOF group, $84 \%$ for the whole group, and $83 \%$ for the comparable non-EOF group as compared to females at $92 \%$ for EOF group, $87 \%$ for the Whole sample, and $86 \%$ for the comparable non-EOF group. Within the three samples Asian students were retained at a higher rate at $93 \%$ for the whole group, $97 \%$ for the EOF group, and $93 \%$ for the comparable non-EOF group. 
Interestingly, Black students were retained at a higher rate in the EOF group at $94 \%$ compared to $81 \%$ for the whole group and $79 \%$ for the comparable non-EOF group. Students in Cohort 4 for the whole sample and comparable non-EOF sample had the highest rate of retention compared to the other cohorts. But, in the EOF group Cohort 3 and Cohort 4 had the same rate of retention at $94 \%$.

Next, developmental course placement in reading showed the highest retention rate for all groups than students placing into essay and math developmental courses. Students who did not place into any math developmental course had a higher retention rate than students who placed into essay, reading, or math developmental. Furthermore, students who did not need to take a developmental essay, reading, or math course had higher retention than students who were placed into essay and math but not those placed into reading. 
Table 4

Crosstabs for Student Characteristics: Whole Sample, EOF \& Non- EOF Samples

\begin{tabular}{|c|c|c|c|}
\hline & \multicolumn{3}{|c|}{ Retained } \\
\hline & Whole Sample & $\mathrm{EOF}$ & Non-EOF \\
\hline 23 and younger & $86 \%$ & $91 \%$ & $86 \%$ \\
\hline 24 and older & $79 \%$ & $89 \%$ & $78 \%$ \\
\hline Male & $84 \%$ & $89 \%$ & $83 \%$ \\
\hline Female & $87 \%$ & $92 \%$ & $86 \%$ \\
\hline Asian & $93 \%$ & $97 \%$ & $93 \%$ \\
\hline Black & $81 \%$ & $94 \%$ & $79 \%$ \\
\hline Hispanic & $84 \%$ & $91 \%$ & $83 \%$ \\
\hline Other race/ethnicity & $82 \%$ & $83 \%$ & $82 \%$ \\
\hline White & $87 \%$ & $87 \%$ & $90 \%$ \\
\hline Cohort1 & $86 \%$ & $89 \%$ & $86 \%$ \\
\hline Cohort2 & $83 \%$ & $84 \%$ & $83 \%$ \\
\hline Cohort3 & $85 \%$ & $94 \%$ & $84 \%$ \\
\hline Cohort4 & $87 \%$ & $94 \%$ & $87 \%$ \\
\hline Cohort5 & $85 \%$ & $93 \%$ & $84 \%$ \\
\hline Essay_dev & $84 \%$ & $91 \%$ & $83 \%$ \\
\hline Non-Essay & $86 \%$ & $91 \%$ & $86 \%$ \\
\hline Read_dev & $86 \%$ & $92 \%$ & $85 \%$ \\
\hline Non-奋ead & $85 \%$ & $89 \%$ & $84 \%$ \\
\hline Math_dev & $90 \%$ & $84 \%$ & $83 \%$ \\
\hline Non-Math & $88 \%$ & $88 \%$ & $88 \%$ \\
\hline Business & $85 \%$ & $91 \%$ & $84 \%$ \\
\hline Science & $86 \%$ & $92 \%$ & $86 \%$ \\
\hline Social science $\&$ & & & \\
\hline humanities & $85 \%$ & $91 \%$ & $85 \%$ \\
\hline Technology & $85 \%$ & $89 \%$ & $85 \%$ \\
\hline Undeclared & $80 \%$ & $90 \%$ & $79 \%$ \\
\hline EOF & $91 \%$ & NA & NA \\
\hline Non-EOF & $85 \%$ & NA & NA \\
\hline
\end{tabular}

Additionally, students who selected science as their first semester major had the highest retention compared to those students from other majors. Science majors in all three groups had higher retention than students in business, social science, and humanities, technology, and undeclared.

Lastly, within the whole sample, students coded EOF had a higher percentage of first semester retention at $91 \%$ compared to those in the comparable non-EOF group at 
$85 \%$. Moreover, EOF students had the highest rate of retention for all variables compared to the whole sample and the comparable non-EOF sample.

\section{Logistic Regression}

\section{Baseline Model}

Whole group. To predict first semester to second semester retention (a binary variable), three logistic regression models were run for the whole group, EOF, and comparable non-EOF groups with all predictor variables included (Gelman \& Hill, 2007). Odds ratio, standard error, and statistical significance for the logistic regression for all three groups are displayed in Tables 7, 8, and 9.

Table 7

Logistic Regression Results for the Whole Sample

\begin{tabular}{|c|c|c|c|}
\hline & OR & $\mathrm{SE}$ & $p$ \\
\hline 23 and younger & 1.200 & .110 & \\
\hline Male & .812 & .077 & $* * *$ \\
\hline Asian & 2.390 & .159 & $* * *$ \\
\hline Black & .804 & .112 & $* *$ \\
\hline Hispanic & 1.029 & .095 & \\
\hline Other & .965 & .121 & \\
\hline Cohort2 & .888 & .115 & \\
\hline Cohort3 & .915 & .119 & \\
\hline Cohort4 & 1.151 & .120 & \\
\hline Cohort5 & .899 & .119 & \\
\hline Essay dev & .987 & .084 & \\
\hline Read_dev & 1.367 & .088 & $* * *$ \\
\hline Math_dev & .597 & .092 & $* * *$ \\
\hline FIRST_GPA & 2.024 & .029 & $* * *$ \\
\hline Business & .930 & .101 & \\
\hline Science & .921 & .103 & \\
\hline Technology & 1.031 & .123 & \\
\hline Undeclared & .774 & .166 & \\
\hline $\mathrm{EOF}$ & 1.721 & .158 & $* * *$ \\
\hline
\end{tabular}


Logistic regression was performed on the whole group (Table 7) to assess the relationship between a number of factors and the odds of student retention at the end of the first semester. The model contained eight independent variables (age, gender, race/ethnicity, college placement test, cohort, first semester GPA, college major, and EOF).

As shown in Table 7, EOF was statistically significant in predicting first semester retention. In particular, the odds of EOF students being retained after the first semester were twice that of comparable non-EOF students $(\mathrm{OR}=1.7, p<.001)$. The finding for EOF confirms the findings from previous studies done on student support services programs (Chaney, Muraskin, Cahalan, \& Goodwin, 1998; Fujita \& Oromaner, 1992; Schivener, Weiss, \& Sommo, 2012), showing that being involved in a student support services program helps to increase retention. The EOF program had a positive effect on retention.

Apart from EOF, gender was shown to be a significant factor. The odds of male students being retained after the first semester was $81 \%(\mathrm{OR}=0.812, p<.007)$ of female students. Females had higher odds of retention than males. This was an expected outcome based on previous studies showing the same result (Astin, 1993; Gutierrez \& Dantes, 2009; Hossler, Shapiro, Dundar, Ziskin, Chen, Zerquera, \& Torres, 2012; Nippert, 2000; Rajasekhara \& Hirsch, 2000; Wohlgemuth, Whalen, Sullivan, Nading, Shelley, \& Wang, 2007).

Although age was shown to be a significant factor in previous studies (BrooksLeonard, 1991; Gutierrez \& Dantes, 2009; Hagedorn, 2010; Lanni, 1997; Leppel, 2002; Windham, 1995), in this study age was not statistically significant in predicting first semester retention. Race/ethnicity was found to be statistically significant in predicting 
first semester retention. Asian and Black were shown to be significant predictors of first semester to second semester retention. Students who were Asian had higher odds of retention than those who were White (reference group). Specifically, in the whole sample the odds of retaining Asian students were twice that of $(\mathrm{OR}=2.4, p<.001)$ White students (reference group). In previous studies Asians were shown to have a higher rate of retention than other ethnic groups (Chaney et al., 1998; Gutierrez \& Dantes, 2009; National Center of Education Statistics, 2012).

Although Asian and Black were significant factors in retention, being Black was related to lower odds of first semester retention. The odds of Black students not reenrolling after the first semester were only $80 \%(\mathrm{OR}=0.804, p<.05)$ that of all other races, which agreed with the findings from earlier studies done on student retention (Chaney et al., 1998; Feldman, 1993; Leppel, 2002; National Center of Education Statistics, 2012).

Among the four cohort groups, none were shown to be statistically significant for students being retained after the first semester. The findings for developmental education were shown to be statistically significant for students placed into reading and math developmental courses. Students placed into a developmental reading course had higher odds of retention than those who enrolled in an essay or mathematics developmental course. The odds of retention after the first semester for students who were placed into a reading developmental course were 1.3 times that of students not placed into reading $(\mathrm{OR}=$ $1.3, p<.001)$. Being placed into mathematics developmental course reduced the odds of retention after the first semester. The odds of students being retained who were placed into a math developmental course were $59 \%(\mathrm{OR}=0.597, p<.001)$ of those students who 
placed into an essay or reading developmental course. Based on previous studies, students placed into remedial courses have lower retention and graduation (Bers \& Smith, 1991; Burley, Butner, \& Cejda, 2001).

As expected, first semester GPA was a statistically significant predictor of first semester retention. A one-point increase in GPA score tended to double the odds of being retained to second semester $(\mathrm{OR}=2.0, p<.001)$. Based on previous studies, college GPA was shown to be the strongest predictor of student retention (Adelman, 2006; BrooksLeonard, 1991; Guiterrez \& Dantes, 2009; Hawley \& Harris, 2005; Kiser \& Price, 2008; Leppel, 2002; Owens, 2003).

Finally, college major was not a statistically significant predictor of first semester retention. Although previous studies did show college major as a significant factor in student retention (Astin, 1993; Craig \& Ward, 2008; Nitecki, 2011; Pascarella \& Terenzini, 2005), this study did not support those previous findings. 


\section{Subgroup Analysis}

Table 8

Logistic Regression Results for the EOF Sample

\begin{tabular}{lcc}
\hline & OR & SE \\
\hline 23 and younger & 1.536 & .490 \\
Male & .794 & .347 \\
Asian & 3.950 & .846 \\
Black & 1.639 & .530 \\
Hispanic & 1.024 & .468 \\
Other & .698 & .503 \\
Cohort2 & .880 & .458 \\
Cohort3 & 2.031 & .516 \\
Cohort4 & 1.546 & .518 \\
Cohort5 & 1.632 & .546 \\
Essay_dev & .903 & .365 \\
Read_dev & 1.910 & .402 \\
Math_dev & .491 & .463 \\
FIRST_GPA & 2.035 & .128 \\
Business & .653 & .479 \\
Science & .730 & .445 \\
Technology & .565 & .479 \\
Undeclared & 1.089 & 1.205 \\
\hline Note. SE = Standard error, OR $=$ Odds ratio. $p<0.05, * * p<0.01, * * * p<.001$.
\end{tabular}

EOF group. Next, logistic regression was performed on the EOF group (Table 8) to assess the relationship between a number of factors and the odds of student retention at the end of the first semester. The model contained seven independent variables (age, gender, race/ethnicity, college placement test, cohort, first semester GPA, and college major).

As shown in Table 8, the only factor within the EOF group to show significance was first semester GPA. First semester GPA was statistically significant in predicting first semester retention. Specifically, a one-point increase in GPA score tended to double the odds of being retained to second semester $(\mathrm{OR}=2.0, p<.001)$. Apart from first semester GPA, no other variables were shown to be significant predictors of first semester retention. 
Based on previous studies, college GPA was shown to be the strongest predictor of student retention (Adelman, 2006; Brooks-Leonard, 1991; Guiterrez \& Dantes, 2009; Hawley \& Harris, 2005; Kiser \& Price, 2008; Leppel, 2002; Owens, 2003).

Even though no other variables were found to be significant predictors of student retention, there were two variables that were noteworthy. There were no gender and race/ethnicity differences found in the EOF group. Males and females in the sample were found to have the same retention rate. All race/ethnicity groups within the EOF sample had the same retention rate. No racial group lagged behind in the EOF sample.

Table 9

Logistic Regression Results for the Non-EOF Sample

\begin{tabular}{lrcc} 
& OR & SE & $p$ \\
\hline 23 and younger & 1.203 & .114 & $* * *$ \\
Male & .812 & .079 & $* * *$ \\
Asian & 2.350 & .162 & $*$ \\
Black & .769 & .115 & \\
Hispanic & 1.029 & .098 & \\
Other & 1.008 & .125 & \\
Cohort2 & .890 & .119 & \\
Cohort3 & .875 & .123 & $* * *$ \\
Cohort4 & 1.132 & .124 & $* * *$ \\
Cohort5 & .875 & .123 & \\
Essay_dev & .989 & .086 & \\
Read_dev & 1.347 & .091 & \\
Math_dev & .602 & .094 & \\
FIRST_GPA & 2.025 & .030 & \\
Business & .942 & .104 & \\
Science & .929 & .106 & \\
Technology & 1.071 & .128 & \\
Undeclared & .771 & .168 & \\
\hline Note. SE = Standard error, OR $=$ Odds ratio. $p<0.05,{ }^{* *} p<0.01, * * * p<.001$. &
\end{tabular}

Non-EOF group. Finally, logistic regression was performed on the non-EOF group (Table 9) to assess the relationship between a number of factors and the odds of 
student retention at the end of the first semester. The model contained seven independent variables (age, gender, race/ethnicity, college placement test, cohort, first semester GPA, and college major).

As shown in Table 9, gender was shown to be a significant factor. The odds of male students being retained after the first semester were $81 \%(\mathrm{OR}=0.812, p<.008)$ of female students. Females had higher odds of retention than males. This was an expected outcome based on the previous studies (Astin, 1993; Gutierrez \& Dantes, 2009; Hossler et al., 2012; Nippert, 2000; Rajasekhara \& Hirsch, 2000; Wohlgemuth et al., 2007).

Although age was shown to be a significant factor in previous studies (BrooksLeonard, 1991; Gutierrez \& Dantes, 2009; Hagedorn, 2010; Lanni, 1997; Leppel, 2002; Windham, 1995), in this study age was not statistically significant in predicting first semester retention. Race/ethnicity was found to be statistically significant in predicting first semester retention. Asian and Black were found to be significant predictors of first semester to second semester retention. Students who were Asian had higher odds of retention than those who were White (reference group). Specifically, in the comparable non-EOF sample the odds of retaining Asian students were twice that of $(\mathrm{OR}=2.4, p<$ .001) White students (reference group). In previous studies, Asians were shown to have a higher rate of retention than other ethnic groups (Chaney et al., 1998; Gutierrez \& Dantes, 2009; National Center of Education Statistics, 2012).

Though Black was also shown to be significant, being Black was related to lower odds of first semester retention. The odds of Black students being retained after the first semester was only $77 \%(\mathrm{OR}=0.769, p<.02)$ that of all other races, which agreed with the 
findings from earlier studies done on student retention (Chaney et al., 1998; Feldman, 1993; Leppel, 2002; National Center of Education Statistics, 2012).

Among the four cohort groups, no cohort was a significant predictor of first semester retention. The findings for developmental education were shown to be statistically significant for students placed into reading and math developmental courses. Students placed into a developmental reading course had higher odds of retention than those who enrolled in an essay or mathematics developmental course. The odds of retention after the first semester for students who were placed into a reading developmental course were 1.3 times that of students not placed into reading $(\mathrm{OR}=1.3, p<.001)$. Being placed into mathematics developmental course reduced the odds of retention after the first semester. The odds of retention for students placed into a math developmental course was $60 \%(\mathrm{OR}=0.602 ; p<.000)$ of those students who placed into an essay or reading developmental course. Based on previous studies, students placed into remedial courses are most likely to have low persistence and graduation (Bers \& Smith, 1991; Burley et al., 2001).

As expected, first semester GPA was a statistically significant predictor of first semester retention. A one-point increase in GPA score tended to double the odds of being retained to second semester $(\mathrm{OR}=2.0, p<.001)$. Based on previous studies, college GPA was shown to be the strongest predictor of student retention (Adelman, 2006; BrooksLeonard, 1991; Guiterrez \& Dantes, 2009; Hawley \& Harris, 2005; Kiser \& Price, 2008; Leppel, 2002; Owens, 2003).

Finally, college major was not a statistically significant predictor of first semester retention. Although previous studies did show college major as a significant factor in 
student retention (Astin, 1993; Craig \& Ward, 2008; Nitecki, 2011; Pascarella \& Terenzini, 2005), this study did not support those previous findings. 


\section{CHAPTER 5}

\section{CONCLUSIONS AND IMPLICATIONS}

This study aims to provide insight into the factors that contribute to student retention, which could help institutions implement intervention strategies to promote student success. More importantly, it helps determine if the retention rate differs between EOF and comparable non-EOF students with similar characteristics, controlling for all academic and demographic factors. The results help increase the understanding of the impact of the EOF program on student retention and facilitate comparing the key factors that contribute to retention of community college students who participated in the EOF program and those who did not even though they had similar qualifications for the program. The study tests the hypothesis that participation in the EOF program would affect student retention positively.

The main research questions that guided the analysis included:

1. What is the distribution of the EOF and non-EOF students in the sample? What are the demographic and academic characteristics of the students in the sample? Are there any differences between the EOF group and the non-EOF comparable group?

2. What is the retention rate among the sample? Are there any differences between the EOF group and the non-EOF comparable group?

3. Controlling for all academic and demographic factors, does participation in the EOF program contribute to a higher retention rate?

4. What other factors are related to retention among the sample? Are there any differences in these relations between the EOF and the non-EOF comparable groups? 
The created model for this retention research was based on the theoretical models of Tinto (1975), Astin (1984), Bean (1985), Bean and Metzner (1985), Pascarella (1985), Cabrera et al. (1992), and Braxton et al. (2011). The new element I proposed was the statefunded program EOF. This new element reflected Tinto, Astin, Bean \& Metzner, and Cabrera, Castanenda, Nora, and Hengstler theoretical models. The models of Tinto, Astin, and Cabrera et al. involved the informal and formal integration the individual has with the college. The financial aid structure for the EOF program related to the models of Astin, Bean \& Metzner, and Cabrera et al., which incorporated aspects of the students' background characteristics and external factors. The major constructs of my new created model included demographic factors (age, gender, ethnicity and race) and academic factors (college placement test, GPA, and college major). The socioeconomic variable was not included in the model, because all students participating in the EOF program and the nonEOF comparable group were low-income students, the income criterion for the EOF program.

The main data source was institutional data from the research site. The sample included five cohorts of community college first-time freshmen students enrolled between the 2008 and 2013 academic years, using the fall semesters as the initial start terms. The sample was separated into the EOF group $(n=570)$, which included first-time freshmen students who participated in the EOF program, and the non-EOF comparable group ( $n=$ $6,535)$ with similar characteristics. The whole sample used in the study was made up of 7,105 first-time freshmen from a community college located in the northeastern United States. 
Based on the proposed conceptual model, I used a three-step analytic approach. The first step was to conduct a logistic regression for the whole sample, using the predictor variables age, gender, ethnicity/race, cohort (Cohort2 - Cohort5), reading, math, essay, GPA, college major (business, science, technology, and undeclared), and EOF. For the second and third steps, I conducted subgroup analysis in which the same model was run for the EOF and non-EOF groups separately, leaving out the EOF variable. The purpose of the subgroup analysis was to investigate the factors that related retention between the two groups and to identify any differences in the predictors across the two groups.

This chapter first briefly concludes the findings presented in Chapter 4, then discusses the implications for policy and practice, theoretical implications, and future research.

\section{Conclusions}

The descriptive analysis provided information about the distribution of retention among the independent variables of age, gender, race/ethnicity, essay, reading, math, college major, and EOF. In general the EOF sample had the higher retention rate for all predictor variables. EOF students had a higher mean and a higher rate of retention in the first semester than comparable non-EOF students.

The EOF sample represented only a small percentage of the entire sample. Race/ethnicity was the demographic characteristic that showed the most percent difference. All races had a higher rate of retention in the EOF group than in the comparable non-EOF group. The race that showed the biggest percent difference was Black; these students were retained at a much higher rate in the EOF group than in the comparable non-EOF group. The academic characteristic that showed the biggest percent difference was college 
placement. Students in the EOF group who were placed in essay, reading, and math developmental courses were retained at a higher percentage than comparable non-EOF students, who were placed in these same courses. Overall looking at all factors, the EOF group was retained at a higher rate than comparable non-EOF students. GPA was the only variable to be statistically significant for the EOF group. The comparable non-EOF group had four statistically significant variables: age, race/ethnicity, read, math, and GPA.

Results of the logistic regression analysis for the three samples were found to be consistent with the literature. A student's participation in the EOF program was positively related to retention in the whole sample. EOF students had higher retention odds than comparable non-EOF students. Male students were negatively related to retention in the whole sample and comparable non-EOF sample. If a student was male he had reduced odds of retention after the first semester. Asians were positively related to retention in the whole sample and comparable non-EOF sample. These students had higher odds of retention than did White students (reference group). Blacks were negatively related to retention in the whole sample and comparable non-EOF sample. Students who were Black had reduced odds of retention compared to White (the reference group) students. Reading developmental was positively related to retention in the whole sample and comparable nonEOF sample. Students who were placed into reading developmental had higher odds of retention than those students not placed into a reading developmental course. Math developmental was negatively related to retention in the whole sample and the comparable non-EOF sample. Those students who were placed into a math developmental course had reduced odds of retention compared to those students who did not have to take a math developmental. Finally, first semester GPA was positively related to retention in all three 
samples. First semester GPA was the strongest predictor of first-semester student retention.

The main factor that was found to be statistically significant in the whole sample, both EOF and comparable non-EOF samples, was first semester GPA. Other factors that were statistically significant in the whole sample and comparable non-EOF sample were gender, race/ethnicity, reading, math, and EOF. Interestingly, in the whole sample and comparable non-EOF sample males and Blacks were negatively related to retention.

Finally, the study hypothesized that participation in the EOF program would impact student retention positively. Based on the data analysis the hypothesis should be accepted. The EOF program, while controlling for all other factors, was still found to be a significant factor in first semester retention. Students participating in the EOF program had higher odds of first semester retention than those students not in the program. Furthermore, the results of the study showed that race/ethnicity difference was reduced in the EOF program but was significant in the comparable non-EOF group. Also gender difference was smaller in the EOF group but was statistically significant in the comparable non-EOF group. The EOF program addressed the gap in gender and race/ethnicity student retention.

\section{Implications for Policy and Practices}

\section{High Risk Factors}

Gender comparison. This research provides an exploration of whether changes in retention are differentially related to gender of students between students in two comparable groups at community college. In my subgroup analysis of whether gender is a predictor of retention in the EOF and comparable non-EOF group, I found it was a significant factor in the comparable non-EOF group but not in the EOF group. This result 
indicates that controlling for all other factors in the comparable non-EOF group, males less likely to enroll to the second semester. To be more specific, the odds of males dropping out are higher in the comparable non-EOF group than those of males in the EOF group.

Moreover, consistent with previous studies, this research indicates that female students tended to persist at higher rates than males (Astin, 1993; Gutierrez \& Dantes, 2009; Ishler \& Craft, 2005; Nippert, 2000; Rajasekhara \& Hirsch, 2000; Wohlgemuth et al., 2007). In addition, gender difference was not evident in the EOF group; whether the student was male or female, he/she persisted at the same rate.

As expected, being male was negatively related to first semester retention. Thus, institutional practitioners may need to take measures at the beginning of their college career to prevent this group of high-risk students from leaving college after the first semester. In particular, based on my study male students in the EOF program had the same odds of retention as female students. I would suggest to policy makers that based on this study the EOF program was shown to reduce gender difference in student retention in the first semester, which could be replicated for all male students to help increase their retention.

Race/Ethnicity comparison. Even after controlling for all other factors, being Black was negatively related to first semester retention. The subgroup analysis demonstrated that being Black was significantly related to retention in the first semester in the comparable non-EOF group but not in the EOF group. To be more specific, students in the comparable non-EOF group who were Black were negatively related to retention in the first semester. However, in the EOF group students who were Black were retained at the same rate as students who were White (reference group). In the EOF group being Black was not related to retention in the first semester as it was in the comparable non-EOF 
group. As suspected, based on previous studies Black students had a lower retention rate than White students (Chaney et al., 1998; Cofer \& Somers, 2001; Feldman, 1993; Gutierrez \& Dantes, 2009; Leppel, 2002; NCES, 2012). National Center of Education Statistics (2012) found that Black and Hispanic students had a lower rate of bachelor degree attainment when compared to White and Asian students. Another study done by Feldman (1993) found that Black students were more likely to drop out, and Leppel (2002) found being Black was related to lower retention, which supports my findings in this study.

Thus, this study provides evidence that there is no race/ethnicity difference for first semester retention for students participating in the EOF program. Policy makers and practitioners need to pay more attention to the disparities of student retention and race/ethnicity. My research supports previous research but gives community colleges more evidence to support programs that increase minority student retention and overall student success. For example programs like the EOF, which is targeted at enhancing the skills of students from disadvantaged backgrounds, should help improve performance and aid retention (Leppel, 2002).

College placement. Mathematics placement was shown to be a statistically significant factor in first semester retention. Previous researchers have found that placement into developmental courses does impact student retention (Bers \& Smith, 1991; Burley et al., 2001). Mathematics in this study was shown to be negatively related to first semester retention. There are lower odds of being retained for a student placed into a math developmental course. The findings for math placement support previous studies done on college placement tests that found developmental courses reduce the odds of student persistence (Bers \& Smith, 1991; Burley et al., 2001; Fike \& Fike, 2008; Hawley \& Harris, 
2005). Developmental education is cited as one the most difficult issues facing community colleges (Bailey \& Cho, 2010; Crisp \& Delgado, 2014). Based on this study more students were placed into math developmental than into reading or English. This increased enrollment in developmental mathematics suggests that more needs to be done to determine what factors influence student success and motivation in learning math (Zientek, Ozel, Fong, \& Griffin, 2013). The previous studies have focused on predictive individual, sociological, and prior educational achievement factors: Although these are important in order to identify at risk students, it is also crucial to measure students' cognitive, motivational, affective, and behavioral variables affecting student success (Zientek et al., 2013). Policy makers and practitioners need to identify variables that are causative in nature to design interventions that can help students improve their learning strategies. A policy maker or practitioner cannot change if a student comes from a low-income family but can facilitate more effective learning strategies and influence students' motivation (Acee, Cho, Kim, \&Weinstein, 2012). Research-based best practices in developmental education should be implemented, including mandatory assessment and placement and systematic program evaluation, to name a few (Boylan, 2002). Further research to assess the impact of developmental education on student retention is necessary.

GPA. Finally, as predicted first semester GPA was the strongest predictor of first semester student retention. Previous research conducted using GPA as a predictor variable showed that it was the best predictor of first-year student retention (Adelman, 2006; Brooks- Leonard, 1991; Guiterrez \& Dantes, 2009; Hawley \& Harris, 2005; Kiser \& Price, 2008; Leppel, 2002; Owens, 2003). Specifically studies by Brooks-Leonard (1991) and Adelman (2006) found that first semester GPA at a community college was significantly 
related to retention. The fact that GPA was the strongest predictor of student retention suggests that what happens to the student after he or she enrolls in college may be more important than the influence of precollege variables (Nakajima et al., 2012). Thus, students' experiences in college may have a significant impact on retention beyond the differences in socioeconomic status, student background, individual attributes, or commitments they may have when they enter college (Nakajima et al., 2012). Therefore, this brings attention to the possibility of enhancing student retention at the community college through institutional policies and practices intended to enhance first semester GPA and its relational factors (Nakajima et al., 2012). Early identification of at-risk students is crucial. Since first semester GPA was the most significant predictor for student retention, colleges should focus on improvement of academic performance among students. One problem is that college practitioners are not likely to notice students who are struggling academically until they start to fail. Therefore, in order to improve academic performance and, thus, improve student retention, it is recommended to policy makers and institutional practitioners to implement a mandatory early warning system to help students in the beginning of the semester, before they fail.

\section{EOF Program and Retention}

Results indicate that after controlling for other factors, the EOF program in the baseline model (whole sample) was found to be a statistically significant factor in first semester student retention. Consistent with prior research student support services programs were shown to have a positive impact on student retention (Chaney et al., 1998; Fujita \& Oromaner, 1992; Scrievener et al., 2012). Thus, the present research suggests that students' involvement in the EOF program increased their odds of first semester retention. 
In prior studies, services provided by student support services programs, like peer tutoring, were shown to help increase student retention. Other institution-funded support services programs were also shown to increase student retention in previous studies: orientation, learning communities, advising, counseling, and mentoring (Alfonso, Bailey, \& Scott, 2005). The findings of this study suggest that the services provided by the EOF program might impact student retention. The EOF program at the research site provides academic, career and personal counseling, along with orientation programs, tutoring, advising, and study skills workshops. Furthermore, controlling for all other factors in the EOF group there was no race/ethnicity or gender differences within this group, which indicates that all the services offered by the EOF program, may be related to student retention.

The results of the EOF program being a significant factor of first semester retention and no race/ethnicity or gender differences in the EOF group have implications for state funded programs in higher education. According to this study, participation in EOF reduces dropout risks for students across gender and all racial/ethnic groups. Given this finding, institutional administrators and state policy makers should increase the amount of funding allocated for EOF, to ultimately increase the number of students who can participate in the program, if improving student retention is a priority. Increasing state funding of the program could also support the integration of institution-funded programs. By blending institutional programs with a state-funded program, higher education policy makers and institutional practitioners would be more effective in raising college retention rates.

\section{Theoretical Implications}


The conceptual model used in this study is an integrated model derived from the theories of Tinto (1975), Astin (1984), Bean (1985), Bean and Metzner (1985), Pascarella (1985), Cabrera et al. (1992), and Braxton et al. (2011). All of the models included in this study incorporated the student background characteristics as predictors of retention. Those background characteristics included demographic, academic, and financial factors. Although the financial factor was not highlighted in the model, it was incorporated in the state-funded program variable. All of the students participating in the EOF program were low income. Also covered in the conceptual model were the academic factors that contributed to retention, including GPA, college placement, and college major. The previous models outlined how these academic factors play a role in retention. All of the academic variables in the created model, except college major, impacted student retention.

Lastly, the model used in this research deepened and expanded on the current theories of student retention. The model created and the approach used to identify the comparable non-EOF group was identified based on the main criteria for selecting EOF students, gross income and household size. The approach allowed us to have a statistically comparable group of at-risk students at a single institution. Previous studies have struggled in identifying comparable groups (Chaney et al., 1998; Noble et al., 2007; Miller et al., 2011; Nguyen et al., 2010). The present study provides evidence demonstrating that research based on the created conceptual model can help determine if a student support services program can predict student retention.

\section{Implications for Future Research}

The research findings, paired with the limited prior studies on community college student retention reviewed in Chapter 2, suggest that more research needs to be done on 
community college, investigating special support services programs designed to help lowincome student retention. Although there are limitations as to what community college can do in order to assist students, the results of this study provide a guide to identify students who are at risk of dropping out of community college. This study also highlights a statefunded program that is working to increase student retention at community college. Administrators, faculty, and counselors at the community college should be aware of the factors that were found to be significant so that greater care can be offered and improved services implemented for students who are at risk.

First, the present study should be replicated for upcoming groups of first-time freshmen students at this community college. In addition, this study should be replicated at four-year institutions. A replication of the study would establish support or lack of support for the logistic models developed in this study. This research supports the use of logistic regression to examine community college student retention. All three logistic regression models were able to identify the significant variables related to student retention. Using this type of analysis clearly identified the significant predictor variables related to first semester retention. Also numerous predictor variables can be employed using logistic regression. The study can be repeated using additional relevant predictor variables. Additional predictor variables such as those related to parent education, students' commitment levels, and learning styles may lead to a greater understanding of student retention (Kiser \& Price, 2008). Including a student's outside commitments may identify factors that contribute to student retention. These predictor variables could include such factors as marital status, number of hours per week the student works (Kiser \& Price, 2008), number of hours per week the student studies, and if the student has dependents. 
These types of factors could add to the results of this study, which found that the EOF program was statistically significant in predicting first semester retention.

Predictor variables incorporating features of the community college, such as orientation, academic bridge programs, and tutoring, could be included and might yield results that would assist faculty and administrators at the institution in establishing policies for their freshmen students. Based on the minimal research on student support services, this research suggests that further research would be beneficial to all students. Replication of this study at multiple community colleges could lead to the understanding of student retention for community college students. Additionally, each college could tailor the model to fit its specific information needs.

Secondly, developmental education needs further research at the community college. A future study could measure developmental education in an alternate way. Instead of using the types of developmental courses the student was placed into, investigating the grade achieved at the end of first semester would enhance the analysis of student retention. Also to know the other courses the student enrolled in the first semester could give additional data needed on first semester retention. These types of data could lead to a better retention model at the community college, which would help to increase student retention.

Finally, a program evaluation for the EOF program could offer additional insight into first semester student retention. Using a program evaluation, a researcher might gain a unique perspective on retention factors by including in-depth observations of the academic and social environment of EOF students. Moreover, a program evaluation might lead to findings related specifically to why EOF students have a higher retention rate than comparable non-EOF students. 
The study of the predictors that lead to first semester retention of community college first-time freshmen is complex. However, constructing a retention model for a community college is likely to assist the institution in obtaining a better understanding of the factors that lead to the retention of their first-time freshmen. Future studies may also lead to discovering additional predictor variables that are statistically significant not only in first semester retention, but also first year retention. The ability to have data relevant to student retention may help guide college practitioners in developing effective retention programs. These retention programs could be for all first-time freshmen and also developed to meet the needs of all students. 


\section{References}

Acee, T. W., Cho, Y., Kim, J. I., \& Weinstein, C. E. (2012). Relationships among properties of college students' self-set academic goals and academic achievement. Educational Psychology, 32(6), 681-698.

ACT. (2004). National collegiate retention and persistence to degree rates. Retrieved, from http://www.act.org/path/policy/pdf/retain_2004.pdf.ACT. (2010a). National collegiate retention and persistence to degree rates. Retrieved from http://www.act.org/research/policymakers/pdf/retain_2010.pdf

ACT. (2010b). What works in student retention? Fourth national survey. Retrieved from http://www.act.org/research/policymakers/pdf/droptables/CommunityColleges.pdf

ACT. (2012). National collegiate retention and persistence to degree rates. Retrieved, from http://www.act.org/research/policymakers/pdf/retain_2012.pdf

Adelman, C. (2006). The toolbox revisited: Paths to degree completion from high school through college. Washington, DC: U.S. Department of Education. Retrieved from: http://www.ed.gov/rschstat/research/pubs/toolboxre visit/toolbox.pdf

Alfonso, M., Bailey, T. R., \& Scott, M. (2005). The educational outcomes of occupational sub-baccalaureate students: Evidence from the 1990s. Economics of Education Review, 24(2), 197-212.

Allen, D. (1999). Desire to finish college: An empirical link between motivation and persistence. Research in Higher Education, 40, 461-486.

American Association of Community Colleges. (2012). A report from the 21st Century Commission on the Future of Community Colleges: Reclaiming the American dream community colleges and the nation's future. Retrieved from 
http://www.aacc.nche.edu/aboutcc/21stcenturyreport_old/index.html

Astin, A. W. (1984). Student involvement: A developmental theory for higher education. Journal of College Student Personnel, 25, 297-308.

Astin, A. W. (1993). What matters in college? Four critical years revisited. San Francisco, CA: Jossey-Bass.

Astin, A. W., Tsui, L., \& Avalos, J. (1996). Degree attainment rates at American colleges and universities: Effects of race, gender, and institutional types (Report No. HE 029589). Los Angeles, CA: Higher Education Research Institute (ERIC Document Reproduction Service No. ED400749).

Bahr, P. R. (2008). Does mathematics remediation work? A comparative analysis of academic attainment among community college students. Research in Higher Education, 49(5), 420-450.Bahr, P. R. (2013). The aftermath of remedial math: Investigating the low rate of certificate completion among remedial math students. Research in Higher Education, 54(2), 171-200.

Bailey, T. R. (2005). Paths to persistence: An analysis of research on program effectiveness at community colleges.

Bailey, T. R., \& Cho, S. W. (2010). Developmental education in community colleges.

Bailey, T., \& Morest, V. S. (2006). Defending the community college equity agenda. Baltimore, MD: Johns Hopkins University Press. Barnett, E. A. (2011). Validation experiences and persistence among community college students. The Review of Higher Education, 34(2), 193-230.

Barefoot*, B. O. (2004). Higher education's revolving door: Confronting the problem of student drop out in US colleges and universities. Open Learning: The Journal of 
Open, Distance and e-Learning, 19(1), 9-18.

Bean, J. P. (1980). Dropouts and turnover: The synthesis and test of a causal model of student attrition. Research in Higher Education, 12(2), 155-187.

Bean, J. P. (1985). Interaction effects based on class level in an explanatory model of college student dropout syndrome. American educational research journal, 22(1), $35-64$.

Bean, J. P., \& Metzner, B. S. (1985). A conceptual model of nontraditional undergraduate student attrition. Review of Educational Research, 55, 485-540.

Benbow, C. P., Arjmand, O., \& Walberg, H. J. (1991). Educational predictors among mathematically talented students. Journal of Educational Research, 84, 215-222.

Berger, J. B. (2000). Optimizing capital, social reproduction, and undergraduate persistence. In J. M. Braxton (Ed.), Reworking the student departure puzzle (pp. 95-124). Nashville, TN: Vanderbilt University Press.

Bers, T. H., \& Smith, K. E. (1991). Persistence of community college students: The influence of student intent and academic and social integration. Research in Higher Education, 32, 539-556.Boggs, G. R. (2011). Community colleges in the spotlight and under the microscope. New Directions for Community Colleges, 2011(156), 322.

Bonham, B. S., \& Boylan, H. R. (2011). Developmental Mathematics: Challenges, Promising Practices, and Recent Initiatives. Journal of Developmental Education, 34(3), 2.

Boylan, H. R. (2002). What works: Research-based best practices in developmental education. Boone, NC: National Center of Developmental Education. 
Boylan, H. R., Bliss, L. B., \& Bonham, B. S. (1997). Program components and their relationship to student performance. Journal of Developmental Education, 20, 2-9.Braxton, J. M. (Ed.). (2000). Reworking the student departure puzzle. Nashville, TN: Vanderbilt University Press.

Bragg, D. D. (2001). Opportunities and challenges for the new vocationalism in American community colleges. New Directions for Community Colleges, 2001(115), 5-15.

Braunstein, A., McGrath, M., \& Pescatrice, D. (2000). Measuring the impact of financial factors on college persistence. Journal of college student retention, 2(3), 191-203.

Braxton, J. M., Hirschy, A. S., \& McClendon, S. A. (2011). Understanding and reducing college student departure: ASHE-ERIC Higher Education Report, Volume 30, Number 3 (Vol. 16). John Wiley \& Sons.

Braxton, J. M., \& Lien, L. A. (2000). The viability of academic integration as a central construct in Tinto's interactionalist theory of college student departure. In J. M. Braxton (Ed.), Reworking the student departure puzzle (pp. 11-28). Nashville, TN: Vanderbilt University Press.

Braxton, J. M., Sullivan, A. V., \& Johnson, R. M. (1997). Appraising Tinto's theory of college student departure. In J. C. Smart (Ed.), Higher education: A handbook of theory and research (Vol. 12, pp. 107-164). New York, NY: Agathon Press.

Brint, S., \& Karabel, J. (1989). The diverted dream: Community colleges and the promise of educational opportunity in America, 1900-1985. New York, NY: Oxford University Press. 
Brooks-Leonard, C. (1991). Demographic and academic factors associated with first-to-second-term retention in a two-year college. Community/Junior College Quarterly of Research and Practice, 15(1), 57-69.

Burley, H., Butner, B., \& Cejda, B. (2001). Dropout and stopout patterns among developmental education students in Texas community colleges. Community College Journal of Research and Practice, 25(10), 767-782.

Burns, K. (2010). At issue: Community college student success variables: A review of the literature. Community College Enterprise, 16(2), 33.

Cabrera, A. F., Burkum, K. R., \& La Nasa, S. M. (2005). Pathways to a four-year degree. College student retention: Formula for student success, 155-214.

Cabrera, A. F., Castaneda, M. B., Nora, A., \& Hengstler, D. (1992). The convergence of two theories of college persistence. Journal of Higher Education, 63, 143-164.

Cabrera, A. F., Nora, A., \& Casteneda, M. B. (1992). The role of finances in the persistence process: A structural model. Research in Higher Education, 33, 571-592.

Cabrera, A. F., Nora, A., \& Castaneda, M. B. (1993). College persistence: Structural equations modeling test of an integrated model of student retention. Journal of Higher Education, 64, 123-139.

Center for Community College Student Engagement. (2005). Engaging students, challenging the odds. Austin, TX: The University of Texas at Austin, Community College Leadership Program.

Center for Community College Student Engagement. (2011). A matter of degrees: Promising practices for community college student success (a first look). Austin, TX: The University of Texas at Austin, Community College Leadership Program. 
Chaney, B., Muraskin, L. D., Cahalan, M. W., \& Goodwin, D. (1998). Helping the progress of disadvantaged students in higher education: The federal student support services program. Educational Evaluation and Policy Analysis, 20(3), 197-215.

Cho, S. W., \& Karp, M. M. (2013). Student success courses in the community college: Early enrollment and educational outcomes. Community College Review, 0091552112472227.

Cofer, J., \& Somers, P. (2001). What influences student persistence at two-year colleges? Community College Review, 29(3), 56-76.

Cohen, A. M., \& Brawer, F. B. (2003). The American community college. John Wiley \& Sons.

Community College Research Center. (2014). What we know about developmental education outcomes. Retrieved from, http://ccrc.tc.columbia.edu/The-Role-of-theCommunity-College.html.Complete College America. (2011). Time is the enemy. Complete College America. Washington, DC.

Conell, J. P, Aber, J. L., \& Spencer, M. B. (1994). Educational risk and resilience in African-American youth: Contest, self, action, and outcomes in school. Child Development, 65, 493-506.

Craig, A. J., \& Ward, C. V. (2008). Retention of community college students: Related student and institutional characteristics. Journal of College Student Retention: Research, Theory and Practice, 9(4), 505-517.

Creswell, J. W. (2005). Educational research: Planning, conducting, and evaluating quantitative and qualitative research. NJ: Pearson Education. 38-58.

Crisp, G., \& Delgado, C. (2014). The impact of developmental education on community 
college persistence and vertical transfer. Community College Review, 42(2), 99117.

Crisp, G., \& Mina, L. (2012). The community college. College student retention: Formula for student success, 147.

Crissman, J. L. (2001). The impact of clustering first year seminars with English composition courses on new students' retention rates. Journal of College Student Retention: Research, Theory \& Practice, 3(2), 137-152.

DAEMPFLE, PH. D, P. A. (2003). An analysis of the high attrition rates among first year college science, math, and engineering majors. Journal of College Student Retention: Research, Theory and Practice, 5(1), 37-52.

Dassance, C. R. (2011). The next community college movement?. New Directions for Community Colleges, 2011(156), 31-39.

Dougherty, K. J., \& Townsend, B. K. (2006). Community college missions: A theoretical and historical perspective. New Directions for Community Colleges, 2006(136), 513.

Durkheim, E. (1950). Suicide: a study in society.

Endo, J., \& Harpel, R. (1982). The effect of student-faculty interaction in students' educational outcomes. Research in Higher Education, 16, 115-170.Escobedo, G. (2007). A retention/persistence intervention model: Improving success across cultures. Journal of Developmental Education, 12-37.

Escobedo, G. (2007). A retention/persistence intervention model: Improving success across cultures. Journal of Developmental Education, 12-37.

Feldman, K. A., \& Newcomb, T. M. (1969). The impact of college on students. 
Feldman, M. J. (1993). Factors associated with one-year retention in a community college. Research in Higher Education, 34, 503-512.

Fike, D. S., \& Fike, R. (2008). Predictors of first-year student retention in the community college. Community College Review, 36(2), 68-88.

Fralick, M. A. (1993). College success: A study of positive and negative attrition. Community College Review, 20, 29-36.

Fujita, E., \& Oromaner, M. (1992). The study of attrition at Hudson County Community College. Status Report. (ERIC Document Reproduction Service No. ED 351083).

Garardi, S. (1996). Factors which influence community college graduation. City University of New York NYC Technical College. (ERIC Document Reproduction Service No. ED 38945).

Goldrick-Rab, S. (2010). Challenges and opportunities for improving community colleges student success. Review of Educational Research, 80, 437-469.

Grosset, J. M. (1991). Patterns of integration, commitment, and student characteristics and retention among younger and older students. Research in Higher Education, 32, $159-178$.

Gutierrez, A., \& Dantes, J. (2009). Practical model for the community college. Community College Journal of Research and Practice, 33(11), 958-961.

Hagedorn, L. S. (2010). Introduction to the issue: Community college retention - an old problem exacerbated in a new economy. Journal of College Student Retention: Research, Theory and Practice, 12(1), 1-5.

Halpin, R. L. (1990). An application of the Tinto model to the analysis of freshman persistence in a community college. Community College Review, 17, 22-32. 
Hauptman, A. M. (2007). Strategies for improving student success in postsecondary education. Changing direction: Integrating higher education financial aid and financing policy. Western Interstate Commission for Higher Education.

Hawley, T. H., \& Harris, T. A. (2005). Student characteristics related to persistence for first-year community college students. Journal of College Student Retention, 7, 117-142.

Hoachlander, G., Sikora, A. C., Horn, L., \& Carroll, C. D. (2003). Community college students. Education Statistics Quarterly, 5(2), 121-128.

Hossler, D., Shapiro, D., Dundar, A., Ziskin, M., Chen, J., Zerquera, D., \& Torres, V. (2012). Transfer and mobility: A national view of pre-degree student movement in postsecondary institutions.

Ishler, J. \& Upcraft, M.L. (2005). The keys to first-year student persistence. Challenging and Supporting the first-year student: A handbook for improving the first year of college, 27-46.

Jarrell, C. L. (2004). Creating a foundation for student success: From research to practice. Community College Journal of Research and Practice, 28(6), 513-524.

Karlen, J. M. (2003). Attrition of women business majors in an urban community college. Journal of College Student Retention Research, Theory, and Practice, 5(1), 1-9.

Karp, M. M. (2011). Toward a new understanding of non-academic student support: Four mechanisms encouraging positive student outcomes in the community college. CCRC Working Paper No. 28. Assessment of Evidence Series. New York, NY: Columbia University, Community College Research Center.

Kasper, H. T. (2002). The changing role of community college. Occupational Outlook 
Quarterly, 46(4), 14-21.

Kiser, A. I., \& Price, L. (2008). The persistence of college students from their freshman to sophomore year. Journal of College Student Retention: Research, Theory and Practice, 9(4), 421-436.

Kubala, K. B. T. (2000). Academic and social integration of community college students: A case study. Community College Journal of Research \& Practice, 24(7), 567-576.

Kuh, G. D. (2009). What student affairs professionals need to know about student engagement. Journal of College Student Development, 50(6), 683-706.

Lanni, J. C. (1997). Modeling student outcomes: A longitudinal study. Paper presented at the 37th Annual Forum of the Association for Institutional Research, Orlando, Florida. (ERIC Document Reproduction Service No. ED410670).

Leppel, K. (2002). Similarities and differences in the college persistence of men and women. The Review of Higher Education, 25, 433-450.

Lewallen, W. C. (1993). Early alert: A report on two pilot projects at Antelope Valley College. Lancaster, CA: Antelope Valley College. (ED 369 452)

MCC EOF. (n.d.). Retrieved February 13, 2013, from http://www2.middlesexcc.edu/services-and-support/education-opportunityfund.html

McClenney, K., Marti, C. N., \& Adkins, C. (2012). Student engagement and student outcomes: Key findings from CCSSE validation research. Community College Survey of Student Engagement.

McElroy, E. J., \& Armesto, M. (1998). TRIO and Upward Bound: History, programs, and issues-past, present, and future. Journal of Negro Education, 373-380. 
McLendon, M. K., Tuchmayer, J. B., \& Park, T. J. (2010). State policy climates for college student success: An analysis of state policy documents pertaining to college persistence and completion. Journal of College Student Retention, 11(1), 33-56.

Miller, C., Binder, M., Harris, V., \& Krause, K. (2011). Staying on track: Early findings from a performance-based scholarship program at the University of New Mexico.

Mullin, C. M. (2012). Why access matters: The community college student body. AACC Policy Brief 2012-01PBL. American Association of Community Colleges (NJ1).

Nakajima, M. A., Dembo, M. H., \& Mossler, R. (2012). Student persistence in community colleges. Community College Journal of Research and Practice, 36(8), 591-613.

Napoli, A. R., \& Wortman, P. M. (1998). Psychosocial factors related retention and early departure of two-year community college students. Research in Higher Education, $39,419-456$.

National Center for Educational Statistics. (2012). The condition of education, 2012 (NCES 2012045). Retrieved from http://nces.ed.gov/pubsearch/pubsinfo.asp?pubid=2012045

Nguyen, A., Hays, B., \& Wetstein, M. (2010). Showing incoming students the campus ropes: Predicting student persistence using a logistic regression model. The Journal of Applied Research in the Community College, 18(1), 16-21.

Nippert, K.A.R.E.N. (2000). Influences on the educational degree attainment of two-year college students. Journal of College Student Retention, 2(1), 29-40.

Nitecki, E. M. (2011). The power of the program: How the academic program can improve community college student success. Community College Review, 39(2), 98-120.

Noble, K., Flynn, N. T., Lee, J. D., \& Hilton, D. (2007). Predicting successful college 
experiences: Evidence from a first year retention program. Journal of College Student Retention: Research, Theory and Practice, 9(1), 39-60.

Nora, A. (1990). Testing qualitative indicators of precollege factors in Tinto's attrition model: A community college student population. Review of Higher Education, 13(3), 337-355.

Office of Postsecondary Access, Support \& Success. (n.d.). Collegiate Development Programs Retrieved February 13, 2013, from http://www.highered.nysed.gov/kiap/colldev/HEOP/

Owens, R. T. (2003). Retention implications of a relationship between age and GPA. College Student Journal, 37, 181-189.

Pascarella, E. T. (1985). College environmental influences on learning and cognitive development: A critical review and synthesis. Higher education: Handbook of theory and research, 1(1), 1-61.

Pascarella, E. T., Smart, J. C., \& Ethington, C. A. (1986). Long-term persistence of twoyear college students. Research in Higher Education, 24, 47-71.

Pascarella, E. T., \& Terenzini, P. (2005). How college affects students: Findings and insights from twenty years of research. San Francisco, CA: Jossey-Bass.

Paulsen, M. B., \& St. John, E. P. (2002). Social class and college costs: Examining the financial nexus between college choice and persistence. The Journal of Higher Education, 73(2), 189-236.

The Pell Institute for the Study of Opportunity in Higher Education. (2009). National studies find TRIO programs effective at increasing college enrollment and graduation. Retrieved from, http://www.pellinstitute.org/publications- 
Studies_Find_TRIO_Programs_Effective_May_2009.shtml

Porter, S. R., \& Swing, R. L. (2006). Understanding how first-year seminars affect persistence. Research in Higher Education, 47(1), 89-109.

Provasnik, S., \& Plantry, M. (2008). Community colleges: Special supplement to The Condition of Education 2008 (NCES 2008-033). Washington, DC: U.S. Department of Education, National Center for Education Statistics, Institute of Education Sciences.

Rajasekhara, K., \& Hirsch, T. (2000). Retention and its impact on institutional effectiveness at a large urban community college.

Reason, R. D. (2009). An examination of persistence research through the lens of a comprehensive conceptual framework. Journal of College Student Development, $50(6), 659-682$.

Rendon, L. I., Romero, J. E., \& Nora, A. (2000). Theoretical consideration in the study of minority student retention in higher education. In J. M. Braxton (Ed.), Reworking the student departure puzzle (pp. 127-156). Nashville, TN: Vanderbilt University Press.

Rifkin, T. (1998). Issues Surrounding the Community College Collegiate Function: A Synthesis of the Literature.

Ross, T., Kena, G., Rathbun, A., KewalRamani, A., Zhang, J., Kristapovich, P., \& Manning, E. (2012). Higher education: Gaps in access and persistence study (NCES 2012-046). U.S. Department of Education, National Center for Education Statistics. Washington, DC: Government Printing Office.

Schmid, C., \& Abell, P. (2003). Demographic risk factors, study patterns, and campus 
involvement as related to student success among Guilford Technical Community College students. Community College Review, 31, 1-16.

Schneider, M., \& Yin, L. (2011). The hidden costs of community colleges. American Institutes for Research.

Schneider, M., \& Yin, L. M. (2012). Completion matters: The high cost of low community college graduation rates. AEI Education Outlook.

Schwartz, R. A., \& Washington, C. M. (1999). Predicting academic success and retention for African-American women in college. Journal of College Student Retention, $1(2), 177-191$.

Scrivener, S., Bloom, D., LeBlanc, A., Paxson, C., Rouse, C. E., \& Sommo, C. (2008). Opening doors. A good start: Two-Year effects of a freshmen learning community program at Kingsborough Community College. $M D R C$.

Scrivener, S., Weiss, M. J., Sommo, C., \& Fresques, H. (2012). What can a multifaceted program do for community college students: Early results from an evaluation of accelerated study in associate programs (ASAP) for developmental education students. Available at SSRN 2089460.

Seidman, A. (Ed.). (2012). College student retention: Formula for student success. Greenwood Publishing Group.

Sharma, S. (1995). Applied multivariate techniques. John Wiley \& Sons.

Spady, W. G. (1970). Dropouts from higher education: An interdisciplinary review and synthesis. Interchange, 1(1), 64-85.

Stage, F. K., \& Hossler, D. (2000). Where is the student? In Reworking the student departure puzzle. Nashville, TN: Vanderbilt University Press. 
State of NJ, Office of the Secretary of Higher Education. (n.d.). Educational Opportunity Fund Program Description Retrieved from http://www.nj.gov/highereducation/EOF/EOF_Eligibility.shtml

State of NY, The State University of New York. (n.d.). Collegiate Development Programs Retrieved from http://www.highered.nysed.gov/kiap/colldev/HEOP/

Strauss, L. C., \& Volkwein, J. F. (2004). Predictors of student commitment at two-year and four-year institutions. Journal of Higher Education, 203-227.

Summers, M. D. (2003). ERIC review: Attrition research at community colleges. Community College Review, 30(4), 64-84.

Swail, W. S. (2000). Preparing America's disadvantaged for college: Programs that increase college opportunity. New Directions for Institutional Research, 2000(107), $85-101$.

Swail, W. S., Quinn, K., Landis, K., \& Fung, M. (2012). A blueprint for success: Case studies of successful pre-college outreach programs. Educational Policy Institute. Retrieved from, http://www.educationalpolicy.org/publications/pubpdf/TG_CASESTUDY.pdf

Tinto, V. (1975). Dropout from higher education: A theoretical synthesis of recent research, Review of Educational Research, 45, 89-125.

Tinto, V. (1987). Leaving college: Rethinking the causes and cures of student attrition. University of Chicago Press, 5801 S. Ellis Avenue, Chicago, IL 60637.

Tinto, V. (2006). Research and practice of student retention: What next? Journal of College Student Retention: Research, Theory and Practice, 8(1), 1-19.

Titus, M. A. (2006). No college student left behind: The influence of financial aspects of 
state's higher education policy on college completion. The Review of Higher Education, 29, 293-317.U.S. Department of Education. National Center for Education Statistics. Low-Income students: Who they are and how they pay for their education, NCES 2000-169, by Susan Choy. Project Officer: Larry Bobbitt. Washington DC:

Townsend, B. K., Donaldson, J., \& Wilson, T. (2005). Marginal or monumental? Visibility of community colleges in selected higher-education journals. Community College Journal of Research \& Practice, 29(2), 123-135.

U.S. Department of Education. National Center for Education Statistics. Remedial education at degree-granting postsecondary institutions in Fall 2000, NCES 2004010, by Basmat Parsad and Laurie Lewis. Project Officer: Bernard Greene. Washington, DC:.Voorhees, R. A. (1987). Toward building models of community college persistence: A logit analysis. Research in Higher Education, 26, 115-129.

Gennep, A. V. (1960). The rites of passage.

Walpole, M. (2003). Socioeconomic status and college: How SES affects college experiences and outcomes. The Review of Higher Education, 27, 45-73.

Webb, M. (1989). A theoretical model of community college student degree persistence. Community College Review, 16(4), 42-49.

Wild, L., \& Ebbers, L. (2002). Rethinking student retention in community colleges. Community College Journal of Research \& Practice, 26(6), 503-519.

Windham, P. (1995). The importance of work and other factors to attrition: A comparison of significancy and odds ratios for different outcomes. Paper presented at the 24th Annual Conference of the Southeastern Association for Community College 
Research, Asheville, NC. (ERIC Document Reproduction Service No. ED 385312)

Wohlgemuth, D., Whalen, D., Sullivan, J., Nading, C., Shelley, M., \& Wang, Y. (2007).

Financial, academic, and environmental influences on the retention and graduation of students. Journal of College Student Retention: Research, Theory and Practice, $8(4), 457-475$.

Xiao, B. (1999). The impact of freshmen year academic success on student persistence and bachelor's degree completion. Paper presented at the Association for Institutional Research, Seattle, WA.

York, C. M., Bollar, S., \& Schoob, C. (1993, August). Causes of college retention: A systems perspective. Paper presented at the meeting of American Psychological Association, Toronto, Ontario, Canada.

Zeidenberg, M., Jenkins, P. D., \& Calcagno, J. C. (2007). Do student success courses actually help community college students succeed?

Zhang, Y., Chan, T., Hale, M., \& Kirshstein, R. (2005). A profile of the student support services program, 1998-1999 through 2001-2002. U.S. Department of Education.

Zientek, L. R., Yetkiner Ozel, Z. E., Fong, C. J., \& Griffin, M. (2013). Student success in developmental mathematics courses. Community College Journal of Research and Practice, 37(12), 990-1010. 